\title{
Article \\ Fundamentals of Building Deconstruction as a Circular Economy Strategy for the Reuse of Construction Materials
}

\author{
Gaetano Bertino $^{1, *(\mathbb{D})}$, Johannes Kisser ${ }^{1} \mathbb{D}$, Julia Zeilinger ${ }^{2}$, Guenter Langergraber ${ }^{3} \mathbb{D}$, Tatjana Fischer ${ }^{4}(\mathbb{D}$ and \\ Doris Österreicher 4 (1D)
}

1 Alchemia-Nova GmbH, Institute for Innovative Phytochemistry \& Closed Loop Processes, A-1140 Vienna, Austria; jk@alchemia-nova.net

2 Department of Water, Atmosphere and Environment, Institute of Waste Management, University of Natural Resources and Life Sciences, Vienna (BOKU), A-1190 Vienna, Austria; julia.zeilinger@boku.ac.at

3 Department of Water, Atmosphere and Environment, Institute of Sanitary Engineering and Water Pollution Control, University of Natural Resources and Life Sciences, Vienna (BOKU), A-1190 Vienna, Austria; guenter.langergraber@boku.ac.at

4 Department of Landscape, Spatial and Infrastructure Sciences, Institute of Spatial Planning, Environmental Planning and Land Rearrangement, University of Natural Resources and Life Sciences, Vienna (BOKU), A-1190 Vienna, Austria; tatjana.fischer@boku.ac.at (T.F.); doris.oesterreicher@boku.ac.at (D.Ö.)

* Correspondence: gaetano.bertino@alchemia-nova.net; Tel.: +43-688-64-74-95-23

Citation: Bertino, G.; Kisser, J.; Zeilinger, J.; Langergraber, G.; Fischer, T.; Österreicher, D. Fundamentals of Building Deconstruction as a Circular Economy Strategy for the Reuse of Construction Materials. Appl. Sci. 2021, 11, 939.

https: / /doi.org/10.3390/ app11030939

Academic Editor: Chiara Giosuè

Received: 27 December 2020

Accepted: 18 January 2021

Published: 20 January 2021

Publisher's Note: MDPI stays neutral with regard to jurisdictional claims in published maps and institutional affiliations.

Copyright: (c) 2021 by the authors. Licensee MDPI, Basel, Switzerland. This article is an open access article distributed under the terms and conditions of the Creative Commons Attribution (CC BY) license (https:// creativecommons.org/licenses/by/ $4.0 /)$.

\begin{abstract}
The construction industry is one of the most environmentally detrimental industries in the world, impacting directly the use of raw materials, their determination of use involving the whole lifecycle, as well as all their surrounding environment. However, within the building sector, the transition from a linear to a circular economy is still at an early stage. Business models need to be reconsidered to include new and improved methods and innovative services that could lead to a net reduction in the use of resources and minimizing the waste disposed on landfills. In this context, an important role in buildings' circularity is "deconstruction", which is understood as a well-considered selective dismantlement of building components, in prevision of a future reuse, repurposing, or recycling. It represents a sustainable alternative to common demolition, which tends to be an arbitrary and destructive process, and although faster and cheaper, it typically creates a substantial amount of waste. The purpose of this article is to analyze the deconstruction potential of buildings and the strategies to apply in order to keep the impacts on the urban environment low. The article aims to facilitate the implementation of circular economy strategies for buildings by proposing common principles for deconstruction as a sustainable alternative to demolition and defining the key points to be applied during the design and planning process regardless of the type of construction system or material used.
\end{abstract}

Keywords: building deconstruction; building deconstructability; design for deconstruction; end-oflife material recovery; material reuse; sustainable construction; building circularity; building lifecycle

\section{Introduction}

The construction sector plays an important role in the global economy, generating about $12 \%$ of the world Gross Domestic Product (GDP) [1] and using many intermediate products, such as raw materials, chemicals, electrical equipment, and related services [2]. This tendency is expected to grow in the near future due to the continuing trend of people living in cities, the increasing migration currents, and the rising public-private partnerships in infrastructure development [1]. However, at the same time, the construction sector represents a major source of waste: globally, buildings account for around $35 \%$ of resources used [3] and $40 \%$ of total energy use [4], consume $12 \%$ of the world's drinkable water, and produce almost $40 \%$ of global carbon dioxide emissions [5]. The sector also generates about one-third of all waste destined for the landfill [6] and is associated with different stages of a building's lifecycle, including the manufacturing of construction products, 
building construction, use, renovation, and the management of building waste, consisting of a wide range of components and different (non-) renewable materials, such as concrete, bricks, gypsum, wood, glass, metals, plastic, solvents and excavated soil, many of which could be recycled [7].

As part of the transition from a linear economy to a circular economy, which recently has raised interest of researchers, policy, governments, and industries around the world $[8,9]$, the current construction practices need to be reconsidered, taking into account new and improved methods and services, minimizing the environmental impacts and allowing the reuse of buildings' components and materials in order to avoid waste and reducing costs. In this overview, the construction sector has a particular relevance: on the economic side, due to the global share of GDP it represents and the number of employees in the sector; on the environmental side, because it can contribute substantially to the reduction of energy demand and mitigate the effects of climate change [10]. Therefore, construction and buildings can be considered a key sector for the transition from linear to circular economy, contributing to resource efficiency, improvement in energy use during the lifecycle of buildings and better quality sustainable materials, more waste recycling, and improved design [11].

In this context, an important role in buildings' circularity is played by the so-called "de-construction", which is understood as "construction in reverse" [12], the ability to dismantle the building part by part avoiding damage, in anticipation of maintaining the value by reuse in different contexts, as an alternative to the classic demolition, which tends to be an arbitrary and destructive process, although faster, and also creating substantial amounts of waste [13]. Construction and Demolition Waste (CDW) diverted from landfills accounts for approximately $20-40 \%$ of the total solid waste stream, and $90 \%$ of the CDW stream is generated during the process of demolition [14]. On the other hand, deconstruction allows substantially higher levels of reuse and recycling of materials compared to traditional demolition processes: up to $25 \%$ of material in a traditional residential structure can be easily reused, while up to $70 \%$ of material can be recycled [15]. Compared to demolition, deconstruction offers the possibility of reuse or recycling of materials and components, contributing to circularity because of less material going to landfill and reducing the requirement for extracting virgin resources; as well, it is a cleaner and more sustainable process than demolition, with less pollution released into the atmosphere and waterways [16].

Although nowadays, there are already strategies that consider the possibility of selective deconstruction and reuse of building components and materials [17-19], currently, less than $1 \%$ of the existing buildings are fully demountable [20]. Deconstruction is not a mainstream concept [12]: the greatest challenge for the application of deconstruction strategies is the fact that throughout history, buildings have always been seen as "permanent" objects that should last as long as possible [21] and therefore without thinking of arrangements for future dismantling. Consequently, tools and techniques for dismantling the existing structures are still under development; in addition, there is a lack of clear planning guidelines with which planners could design with foresight and include deconstruction planning in their design process. The current lack is also amplified by the fact that the building stock consists of a wide variety of different types and ages, ranging from buildings built in recent centuries, but still used by the population as residences and small businesses, to more recent buildings in masonry or in reinforced concrete, sometimes even altered over time [22]. A huge panorama of buildings is realized with techniques and methods (regarding their construction and subsequently their "deconstruction" at the end of life) that vary enormously according to the structural type, the connections between the elements that make up the building, and the type of materials used. Therefore, these factors determine a certain level of buildings' deconstructiveness and are essential to know in order to obtain truly valid deconstructive strategies as an alternative to demolition and thus achieve environmental sustainability and economic affordability.

This research article presents how building deconstruction could contribute to the circularity of the sector, allowing to keep building components and materials within the 
production cycle, following a hierarchical scale where "reuse" is preferable to "recycle", which is preferable to "downcycle", which is preferable to "disposal". The research focuses on buildings at different levels of detail: first, analyzing the main common constructive systems, namely the load-bearing parts; then analyzing the various building's components that make up the entity (such as walls, beams, pillars, foundations, partitions, etc.) and the possible ways they are connected with each other. Breaking down the building for the definition of single elements and materials, the aim is to identify the architectural techniques and procedures that best suit the need to dismantle rather than demolish. Attention is paid to possible strategies to avoid demolition and disposal to landfill, considering the different types of existing buildings, with most of them having not been designed for deconstruction. Some real-life examples, where different deconstruction strategies were applied, are presented with the objective of pointing to the positive impact they had in the context in which they were built and "de-built".

The purpose of this research paper is to have a set of deconstruction recommendations, with methods and strategies to apply independently on the different constructive systems and materials, that can enable more sustainable solutions for the end of life of buildings, in a construction sector where buildings are mostly designed to be demolished and not deconstructed. A new clear methodology about deconstruction is proposed to be applied to the construction of buildings from the initial concept to the design phase in order to be effective throughout the building's life cycle. The new methodology will be based on a "step-by-step" approach that considers buildings as independent objects, with different possibilities of construction, deconstruction, and reuse (and therefore not as homogeneous entities to be dismantled, as compared to the destructive approach of demolition). The development of an analysis grid will allow the comparison of different lifecycles for different types of buildings with the aim of defining the specific added value and the deconstruction possibilities. The goal is to recognize deconstruction as a parameter that must be part of the design and planning phase of any building. Similar to a holistic planning approach where energy or resource efficiency are part of the initial design, the potential for deconstruction should be an intrinsic aspect of the design rather than an afterthought. The application of a flexible deconstructive methodology and the reuse and recycling of the deconstructed elements as alternatives to incineration or waste disposal keep building components and materials within the production cycle, helping make the construction sector more circular and subsequently more sustainable.

\section{Background}

From a historical perspective, it is interesting to note that the reuse of building materials, deconstructed and taken from previous constructions no longer in use, is quite common throughout human life [23]. Many specific examples of reuse assumed precise artistic characteristics in the Roman cities of the late ancient period and later throughout the medieval era [24]. An example is the triumphal arch of Constantine, which was built around the year 315 and located in Rome (Italy) at a short distance from the Colosseum (Figure 1). The monument can be considered as a historical "museum" of Roman art, as most of the sculptures and decorations consist of elements removed from previous triumphal monuments dedicated to the emperors Trajan, Hadrian, and Marcus Aurelius [25]. In particular, the frame of the main order, the Corinthian capitals, the shafts in ancient yellow marble, and the bases of the columns are all elements of reuse, affecting a historical period of more than a century, as well as the monumental decorative scheme of the reliefs. They recall the figures of the "good emperors" of the second century (mentioned above) to whom the figure of Constantine is assimilated, who, for propaganda purposes, ideologically proposed himself as the restorer of that past glorious era [26]. 


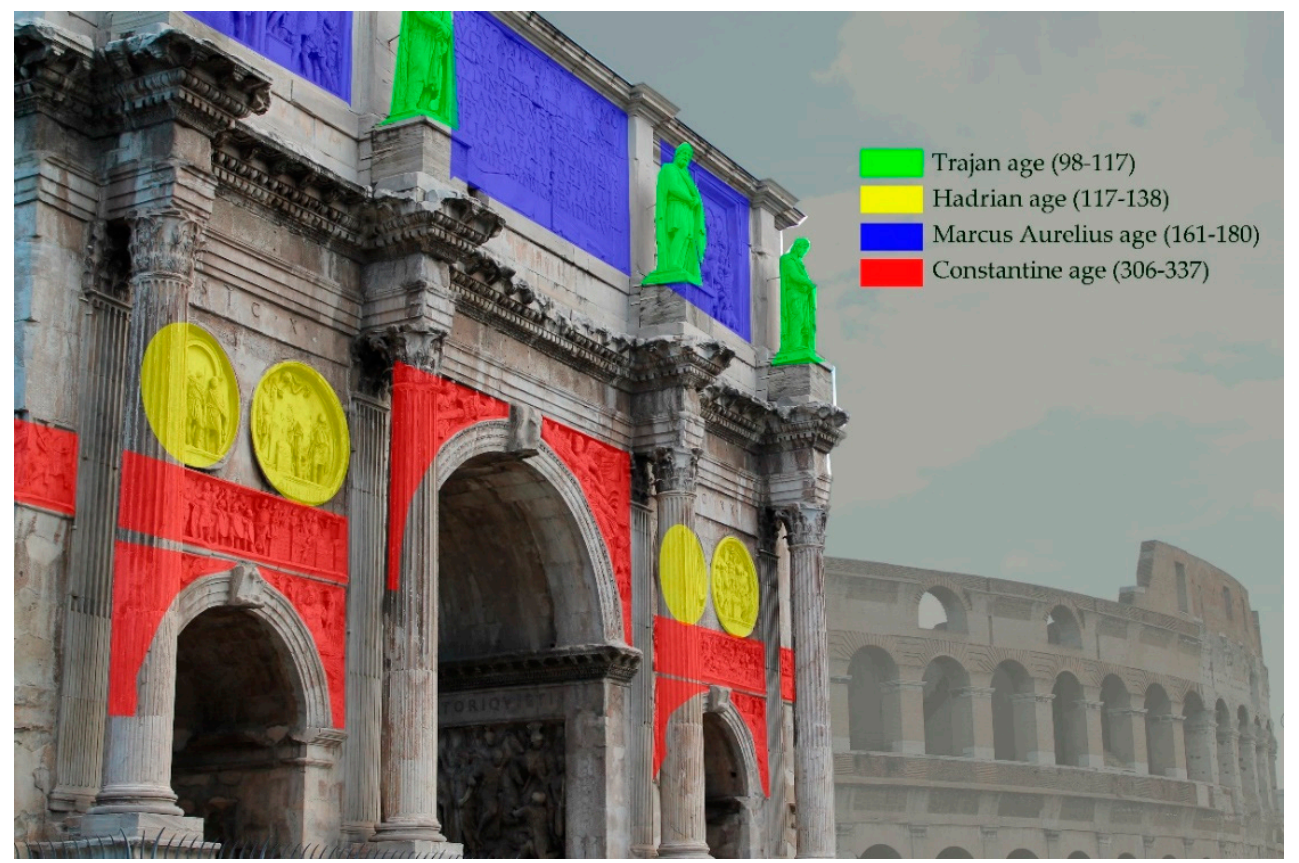

Figure 1. The reliefs of the arch of Constantine, reused from buildings of previous emperors (picture of Sara Torda from Picabay, drawings of G.B.).

Another interesting example of historical reuse of building components is the bell tower in front of the church of "Santa Maria Maggiore della Pietrasanta" in Naples (Italy, Figure 2), which is datable to the 10th or 11th century and is a rare evidence of Romanesque architecture in the city. This structure can be considered as a kind of "patchwork", since it retains numerous architectural elements and inscriptions dating back to the period from the Roman to the High Middle Ages, as the beautiful marbles were reworked and reused as building blocks at the base of the structure. This unusual way to reuse marble is due to the fact that a large Roman temple dedicated to the Goddess Diana stood in the same place in Roman times [27]. On the side of the base overlooking the main street and integrated in the medieval red brick masonry, a block of inlaid marble and an altar, columns, architectural friezes and trabeations, blocks of lava stones (used to pave streets in Roman Ages), and even a slab of "ludus latrunculorum", a game similar to chess very popular between Roman soldiers, are noticeable.

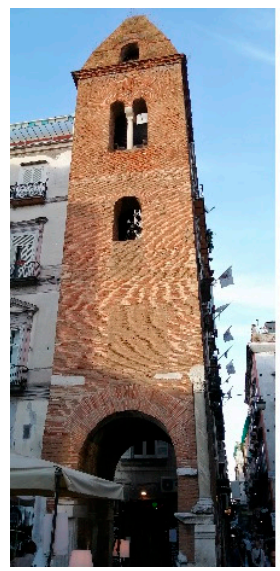

(a)

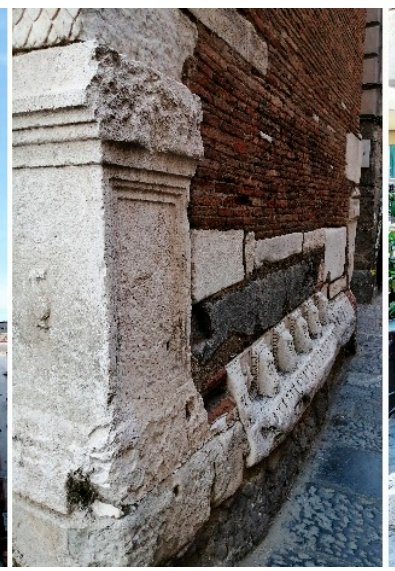

(b)

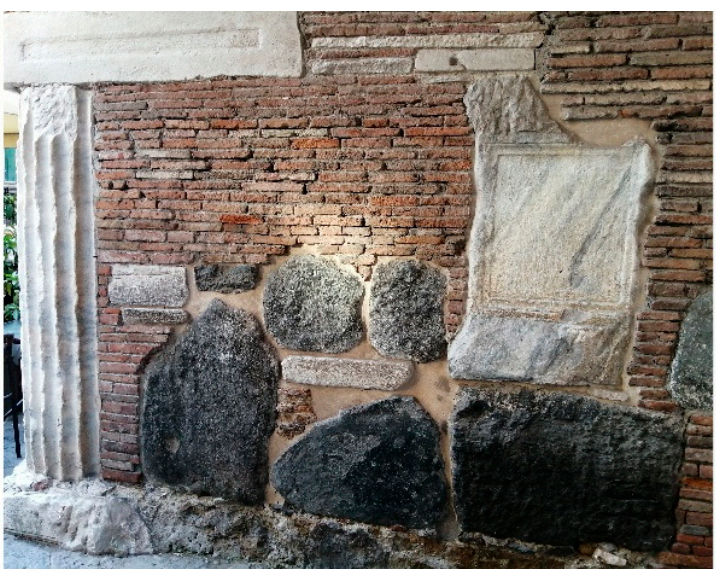

(c)

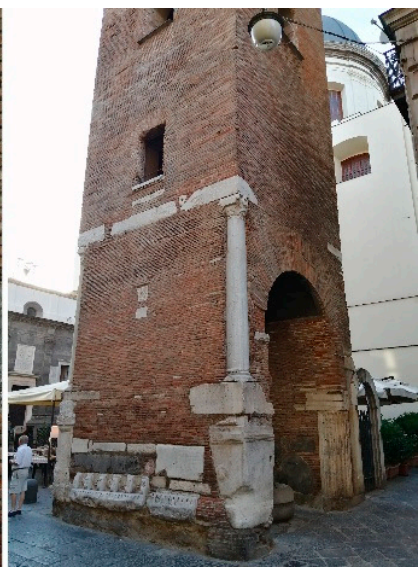

(d)

Figure 2. Bell tower of "Santa Maria Maggiore della Pietrasanta" (pictures of G.B.): (a) Bell tower front view; (b) Detail of the base facing the street; (c) Detail of the base; (d) Bell tower back view. 
"Pont de la Concorde" in Paris can also be mentioned. It is a bridge that crosses the Seine between Place de la Concorde and Quai d'Orsay, opposite the headquarters of the National Assembly. The bridge was built at the end of the 18th century to facilitate the passage between one bank and another in an area that at the time was served only by boat. Since most of its construction was carried out in the middle of the revolutionary era (1787-1791), building materials from the destruction of the Bastille, whose capture by the people marked the beginning of the French Revolution, were also used as building material. In particular, part of the ashlars of the destroyed prison-fortress (seen by the people as a symbol of monarchical power) was used to pave the bridge, so that the Parisians could step every day on this symbol of oppression [28].

In the past, the phenomenon of reuse had a double significance: the reuse of sculptural or architectural elements taken from monuments of previous empires or dynasties has value both in a "triumphal" sense, as spoils of defeated enemies, and in a "renewal" sense, as a re-appropriation of the glories of the past. From a more pragmatic point of view, it underlines the advantage of reusing ready-made materials in comparison to the production of new blocks [29]. The material from ancient buildings combined the intrinsic value of the raw material antiquity of its original use. Of course, this value is no longer applicable in modern society due to the protection of historical assets that do not allow the stripping of the finds. However, the concept of economic savings remains and seems to fit well into the context of the deconstruction of a building for future purposes of reuse or recycling.

\section{State of Knowledge}

In more recent times, starting with the industrial revolution and the exponential acceleration of the production processes and technology that it entailed, demolition emerged as one of the city's management tools to maintain its proper functioning [30]. It contributed to the economic development but contributed little to sustainable environmental development, due to the high amount of demolition waste and no consideration for the reuse or recycling of the buildings' components [31].

Nowadays, the progress of technology has led to the appearance of new methods for buildings' requalification, which are better integrated in the modern context close to the themes of sustainable development and environmental protection, including building deconstruction. There are already plans and execution strategies aimed at considering the deconstruction of buildings. For example, "Building Information Modeling" (BIM) is a method for the optimization of planning, construction, and management of buildings that includes all information relating to their lifecycles and that connects all the actors of the building process along the different stages of the supply chain (design, procurement, construction). It is based on a virtual model, a "digital twin" equivalent to the real building, thus having many details regarding the composition of the materials of each element. This subsequently allows determining the extent to which the building could be deconstructed, right from the design stage, to avoid demolition after the end of the lifecycle [16]. Another example is the so-called "Design for Deconstruction" (DfD), which is intended as a way to design buildings from the outset to allow future changes and the deconstruction of components and materials, including provisions for reuse and the recycling of building components after their dismantling [17]. In DfD, each building is seen as a repository of resources, which at the end of its lifecycle, instead of ending up in a landfill, should find its way back to the "reduce-reuse-recycle" concept. Then, it should be followed by a "deconstruction plan" to ensure that construction processes will allow the deconstruction activities to be successful. Among the various documents produced, the so-called "Material Passport", a list of building elements and how they will be best reused, reclaimed, or recycled in a changing-materials market, is probably the most wellknown. It is currently developed by several organizations in mainly European countries, fitting in the circular context relating to materials [18]. The Material Passport consists of a series of data describing the characteristics of the building's elements, including a complete 
description of all products (windows, doors, staircases, etc.), components (iron beams, glass panels, etc.), and raw materials (wood, steel, etc.) that are present in the building, with the aim of providing value for recovery, recycling, and reuse of the mentioned parts after deconstruction [19].

In this regard, more recent initiatives and regulations were defined at the European level. In 2014, the European Commission promoted the reduction of resource use through the building's lifecycle by the use of deconstruction strategies and the reuse and recycling of products and materials otherwise destined for landfill [32]. In 2015, the European Commission underlined again the importance of encouraging design improvements that will reduce the environmental impacts and increase the durability and recyclability of building components, mentioning the building and construction sector as one of the five priority areas on which the application of circular strategies is based [33]. In 2020, the European Commission drafted the second "EU Action Plan for the Circular Economy", which provides a future-oriented agenda for achieving "a Cleaner and More Competitive Europe" [34]. It presents a set of interrelated initiatives to establish a coherent product policy framework that will make sustainable products, services, and business models, transforming consumption patterns so that no waste is produced in the first place. The EU Action Plan sets the building sector as a priority and promotes circularity principles throughout the entire lifecycle of buildings, with particular attention to construction and demolition waste [35].

Following the push of these initiatives and regulations, the scientific research in the field of deconstruction has made progress, especially in regard to the feasibility of deconstructing a building, considering the possible barriers encountered at the local level from a legislative, economic, and technical point of view. An interesting report about the feasibility of deconstruction was carried out by the Partnership for Advancing Technology in Housing (PATH), which is based on a study on four urban communities in the United States and lessons from other local deconstruction initiatives [36]. It describes the typical conditions under which deconstruction usually takes place, as well as the barriers (economic, organizational, and public policy) that must be overcome for the deconstruction strategy to be effective. In this study, public housing authorities and community leaders are directly addressed who may want to consider deconstruction as a way to enhance and improve their community revitalization efforts [36]. Another recent study was conducted by the Ellen MacArthur Foundation in collaboration with Google, consisting in an initial exploration into the importance of deconstructing commercial buildings and the reuse of building materials for an increasingly circular built environment [37]. It was developed based on insights from interviews with leading deconstruction and reuse experts, primarily in the United States and Europe, and it focuses mainly on the systemic barriers to scaling deconstruction, such as existing buildings that are not designed for easy deconstruction, regulatory frameworks that discourage deconstruction, and marketplaces for reusable materials that are still underdeveloped. The main outcomes from this research are recommendations for project teams and municipalities to increase deconstruction and the reuse of commercial building components, which include the use of DfD right from the design stage, the development and implementation of regulations that encourage deconstruction at the local level, and the geographical expansion of marketplaces for materials to be reused [37].

It appears that the discussion on building deconstruction is widening but not yet at the point of being seen as a priority element by most of the professionals (architects, companies, municipalities), to be considered from the very beginning of the project as it is increasingly happening for other relevant topics such as e.g., energy and resource efficiency.

\section{Materials and Methods}

To be able to analyze the deconstructive potential of a building, it is first of all necessary to know how its entire lifecycle works, starting from its origin: the concept behind its construction, the local context, the choice and origin of materials, and the different types of environmental potential due to what happens in each of the phases that make up the 
lifecycle of the building. This approach allows understanding how each choice made in the design and production phase then has repercussions in the use and disposal phase. Through an in-depth analysis of the "building" object, and of the variety of construction systems and building components that can be found in the construction panorama, it will be possible to evaluate how the degree of deconstruction changes according to the materials and construction techniques used. Finally, some examples of buildings made with deconstructive principles will be shown, where deconstruction has been successful and has led to positive results in the most varied ways.

The aim is to provide a clear methodology to guide the deconstruction process, to be applied for the construction of new buildings, with a "step-by-step" approach that identifies each building differently according to their characteristics and components, but with the clear requirement to consider deconstruction as a fundamental element of building programming and planning. The development of an analysis grid will allow the comparison of different life cycles for different types of buildings, with the aim to define the specific added value and the deconstruction possibilities. The novel approach would implement deconstruction strategies and options for the realization of the building of the future toward a more circular construction sector.

\subsection{A Building's Lifecycle}

A building's lifecycle can be divided into five different stages: design, production, construction, use, and end of life. At the end of life, building components can become an environmental burden by being landfilled or have positive impact by feeding them back to the production stage, reducing the extraction of raw materials [38]. The first phase is the "design", which is a process that, starting from technical standards, calculations, and drawings, leads to the definition of the dictates, guidelines, and specifications necessary for the construction of a building; these are summarized within a project. In a broader sense, the design phase is the set of "planning" and "programming" phases that will lead to an expected result, which can be achieved totally, partially, or even missed [39]. Ultimately, based on the choices made in this stage, the subsequent phases and the possibilities for the end of the lifecycle are a direct consequence. During the production phase, raw materials are extracted, transported, and transformed into construction materials. The extraction of natural resources has a great impact on the availability of non-renewable resources and, moreover, a large amount of water and energy are linked to this process, and this leads to the release of air pollutants [5]. The construction phase is when the building takes its shape. It can last a few years, and it requires a significant amount of energy and materials and involves a large number of actors and equipment. The use phase is generally considered to be the longest in the lifecycle of the building and includes activities such as maintenance, which is aimed at extending the life of the building. The use phase leads to environmental impact caused by user behavior, regarding the use of energy and water consumption and waste generation [6]. Since the linear economy is still prevalent, the end of life of buildings is the demolition process. Demolition creates huge amounts of bulk waste, and the environmental impact of this phase is also related to the release of green gas emissions from machinery and transport, as well as emissions related to the landfill disposal [40]. The end-of-life phase, in the context of the circular economy, is ideally never reached, as the materials are integrated into a second-life continuously: buildings can be disassembled into different components, so they can be reused, repaired, refurbished, or recycled.

\subsection{The Building's End of Life}

The concept of both demolition and deconstruction means that buildings are expected to be used for a predicted period of time; after that, there is the need to find a solution for them. According to the literature, there are different possibilities about buildings' after-life options: maintenance, refurbishment, demolition, and deconstruction [30,41-43].

The maintenance is the set of improvement, preventive, and corrective actions, the purpose of which is not dictated by an urgent need to restore the optimal level of operation but 
rather by an economic management of the maintained system. Over time, the performance requirements increase and new technologies appear on the market, so there is the need to evaluate the replacement of a system (dismantling with demolition or deconstruction) or its maintenance in order to update it and reduce its degree of obsolescence, as well as increase its longevity [43]. The refurbishment is the set of interventions aimed at transforming the building through a systematic set of works that can lead to a building totally or partially different from the previous one. These interventions include the restoration or replacement of some components of the building, as well as the elimination, modification, and insertion of new components and systems. Among the advantages of this process, there is the use and preservation of the historical building heritage, and it offers a sustainable approach to refreshing buildings without disruption and demolition waste but, at the same time, it is a much more expensive process than the demolition and reconstruction of the building with the same volume [42]. Demolition can be intended as the arbitrary disassembling or destroying of a structure in order to quickly clear the construction site. It is a relatively fast and very economical process, but at the same time, it is not necessarily respectful of the environment given the large amount of material destined for landfill. For smaller buildings, the demolition process is quite simple and is done with machinery such as cranes, excavators, bulldozers, and wrecking balls [30]. Finally, deconstruction can be intended as the selective dismantling piece by piece of building components for the purpose of material recovery and components reuse [41].

Table 1 summarizes the possible building's end-of-life concept.

Table 1. Building's end-of-life concept.

\begin{tabular}{ccl}
\hline Destiny & \multicolumn{1}{c}{ Definition } & \multicolumn{1}{c}{ Characteristics } \\
\hline $\begin{array}{c}\text { Maintenance } \\
{[43]}\end{array}$ & $\begin{array}{c}\text { Process of interventions concerning repair, renovation, } \\
\text { and replacement of building parts without altering the } \\
\text { overall volume and without changing the intended use }\end{array}$ & $\begin{array}{l}\text { Quick and easy } \\
\text { Constant over time } \\
\text { Relatively cheap }\end{array}$ \\
$\begin{array}{c}\text { Refurbishment } \\
\text { [42] }\end{array}$ & $\begin{array}{c}\text { Process of restoring a structure to a former better } \\
\text { condition or to revive it, including alterations such as } \\
\text { remodeling and retrofitting, which can result in a } \\
\text { completely different building }\end{array}$ & $\begin{array}{l}\text { Heritage } \\
\text { preservation } \\
\text { Relatively expensive }\end{array}$ \\
\hline $\begin{array}{c}\text { Demolition } \\
{[30]}\end{array}$ & $\begin{array}{c}\text { Process of arbitrary disassembling or destroying of a } \\
\text { building in order to quickly clear the construction site, } \\
\text { with the use of heavy construction machineries }\end{array}$ & $\begin{array}{l}\text { Quick and easy } \\
\text { Very cheap } \\
\text { Common method }\end{array}$ \\
\hline $\begin{array}{c}\text { Deconstruction } \\
\text { [41] }\end{array}$ & $\begin{array}{c}\text { Process of selective dismantling of building components, } \\
\text { part by part and avoiding damage, specifically for reuse, } \\
\text { repurposing, and recycling }\end{array}$ & $\begin{array}{l}\text { Relatively } \\
\text { labor-intensive } \\
\text { Component reuse } \\
\text { Material recycling }\end{array}$ \\
\hline
\end{tabular}

Being the key topic of the present research, the discussion focuses mainly on deconstruction as an alternative to demolition. The deconstruction activity automatically leads to considerations about the subsequent use of the dismantled building components and the different possibilities for their destinies, such as reuse and relocation of the entire building, components reuse in other buildings, material reprocessing, and material recycling $[13,41,44-51]$. The reuse of the entire building for a relocation is the process by which a building is moved from the place where it is located to another one. The techniques used are essentially two: the disassembly of the structure and then the assembly of the same in the place of destination or the movement of the entire structure by the use of temporary rails or platform on wheels in case of long distances [41]. The building is typically lifted in small increments from the foundations by a temporary steel structure with a network of hydraulic jacks placed under the structure and controlled by a unified lifting system. Once the structure is at the required height, hydraulic carts are placed under the steel structure to support the movements to the new destination. After moving, the structure is lowered by reversing the steps just applied [44]. It is a clean process that involves the total reuse of the 
building, but it is a quite expensive and difficult in operation, and it is usually possible only when the building has been designed for deconstruction [45]. Furthermore, the overall sustainability performance of the relocation process is very dependent on the transport distance and local circumstances.

The component reuse in other buildings is the process where the building parts are dismantled during deconstruction and are relocated in new contexts and reused in new lifecycles, which may be related to the construction sector or others. These components that are usually specifically selected in the design phase can be reused without any type of requalification or reprocessing operation, so they are ready to be used in a new lifecycle, although without excluding possible operations of cleaning before the re-mounting operations. It is a process that is already successfully applied, as it is now common to find second-hand component markets, but it must be taken into account that this process has time limits and that therefore, sooner or later, every building component will have to be reprocessed or recycled when it is no longer suitable for the intended functions $[13,49]$.

Material reprocessing consists in the reuse of building components after deconstruction for relocation and reuse, but only after a process of refurbishment or reprocessing that is needed before the component could be reused in a new lifecycle. Compared to the previous case, the "material reprocessing" requires an additional amount of energy due to the need to adapt the element before reusing it. The result of reprocessing is to obtain a product that has either the same characteristics that it had at the beginning of its lifecycle or different characteristics: better in the case of upcycling, worse in the (more common) case of downcycling. Downcycling is the recycling process where the new recycled material is of lower quality and functionality than the original material, due to the presence of pollutants, safety concerns, and/or acceptance, which do not allow high-quality applications. An example is the concrete coming from demolition activities: once crushed, this can be used for lower performance materials such as substrates or screeds, but it cannot be recycled into structural parts, thus obtaining another concrete with equal performance $[48,51]$.

Finally, material recycling can be an option if reuse is not applicable, allowing more products, components, and materials of a building to re-enter the supply chain. It involves a set of strategies and methodologies aimed at recovering useful materials from waste in order to reuse them rather than dispose of them directly in landfills. Therefore, the recycled material prevents wasting potentially useful materials, often improves sustainability in the production and use of materials, and reduces the consumption of raw materials, use of energy, and emission of associated greenhouse gases $[47,50]$. In addition to this, a number of direct and indirect external environmental impacts, such as air pollution and water contamination, which occur through the extraction of raw materials, can also be avoided by reusing recycled materials [52]. Following, Table 2 summarizes the possible building's deconstruction destinies.

Table 2. Building's deconstruction destinies.

\begin{tabular}{|c|c|c|}
\hline Destiny & Considerations & Process \\
\hline $\begin{array}{l}\text { Reuse of entire building } \\
{[[44,45]}\end{array}$ & $\begin{array}{l}\text { Process of moving the building to a new place. It } \\
\text { involves the recovery of all the buildings components } \\
\text { without generation of waste, but it is expensive and } \\
\text { not always possible }\end{array}$ & $\begin{array}{l}\text { 1. Deconstruction } \\
\text { 2. Transportation } \\
\text { 3. Storage } \\
\text { 4. Construction }\end{array}$ \\
\hline $\begin{array}{l}\text { Components reuse in other } \\
\text { buildings } \\
{[13,49]}\end{array}$ & $\begin{array}{l}\text { Process of reusing building components after } \\
\text { deconstruction for relocation and reuse in new } \\
\text { lifecycles, without or only with minimal additional } \\
\text { energy for refurbishment or reprocess }\end{array}$ & $\begin{array}{l}\text { 1. Deconstruction } \\
\text { 2. Transportation } \\
\text { 3. Storage } \\
\text { 4. Construction }\end{array}$ \\
\hline $\begin{array}{c}\text { Material reprocessing } \\
{[48,51]}\end{array}$ & $\begin{array}{l}\text { Process of reusing building components after } \\
\text { deconstruction for relocation and reuse, requiring } \\
\text { additional energy for refurbishment or reprocess. It } \\
\text { involves the possibility that the element could be up- } \\
\text { or down-graded }\end{array}$ & $\begin{array}{l}\text { 1. Deconstruction } \\
\text { 2. Transportation } \\
\text { 3. Reprocessing } \\
\text { 4. Construction }\end{array}$ \\
\hline
\end{tabular}


Table 2. Cont.

\begin{tabular}{cll}
\hline Destiny & \multicolumn{1}{c}{ Considerations } & \multicolumn{1}{c}{ Process } \\
\hline & \multicolumn{1}{c}{ Process of converting the deconstructed waste } & 1. Deconstruction \\
Material recycling & components into new materials and objects. It involves & 2. Transportation \\
{$[47,50,52]$} & the reduction of the consumption of raw materials and & 3. Recycling \\
& prevents the potential waste destined to landfill & 4. New lifecycle \\
\hline
\end{tabular}

The building's deconstruction destinies analyzed above present a certain hierarchy relating to the "sustainable" result obtained, from the reuse of the entire building or of its individual parts, to the reprocessing of materials not ready for reuse, up to the recycling of materials that cannot be reused. As a rule of thumb, to obtain the best possible result from a sustainability point of view, the first option is the most favorable, and the next option should be considered only if the previous one is not feasible, due to the different levels of deconstruction that a building may have [53].

Regarding the possible destinies of a building at the end of its lifecycle, it is possible to define a hierarchical system of preference, as shown in Figure 3. At the base of the hierarchy, there are waste disposal and energy recovery through waste-to-energy, which are the least sustainable methods, but also, those are currently the most used; they are a direct consequence of demolition practices. By deconstruction, on the other hand, it is possible to act in a more sustainable way, since it allows, in ascending order of preference, the recycling of materials, the reprocessing of materials, the reuse of building components, and the relocation of buildings to other sites. While such practices are more sustainable, their application is still limited compared to conventional linear industry ones. To achieve circularity in the sector, therefore, it is necessary to "reverse" the hierarchical system, with a greater use of sustainable methods.

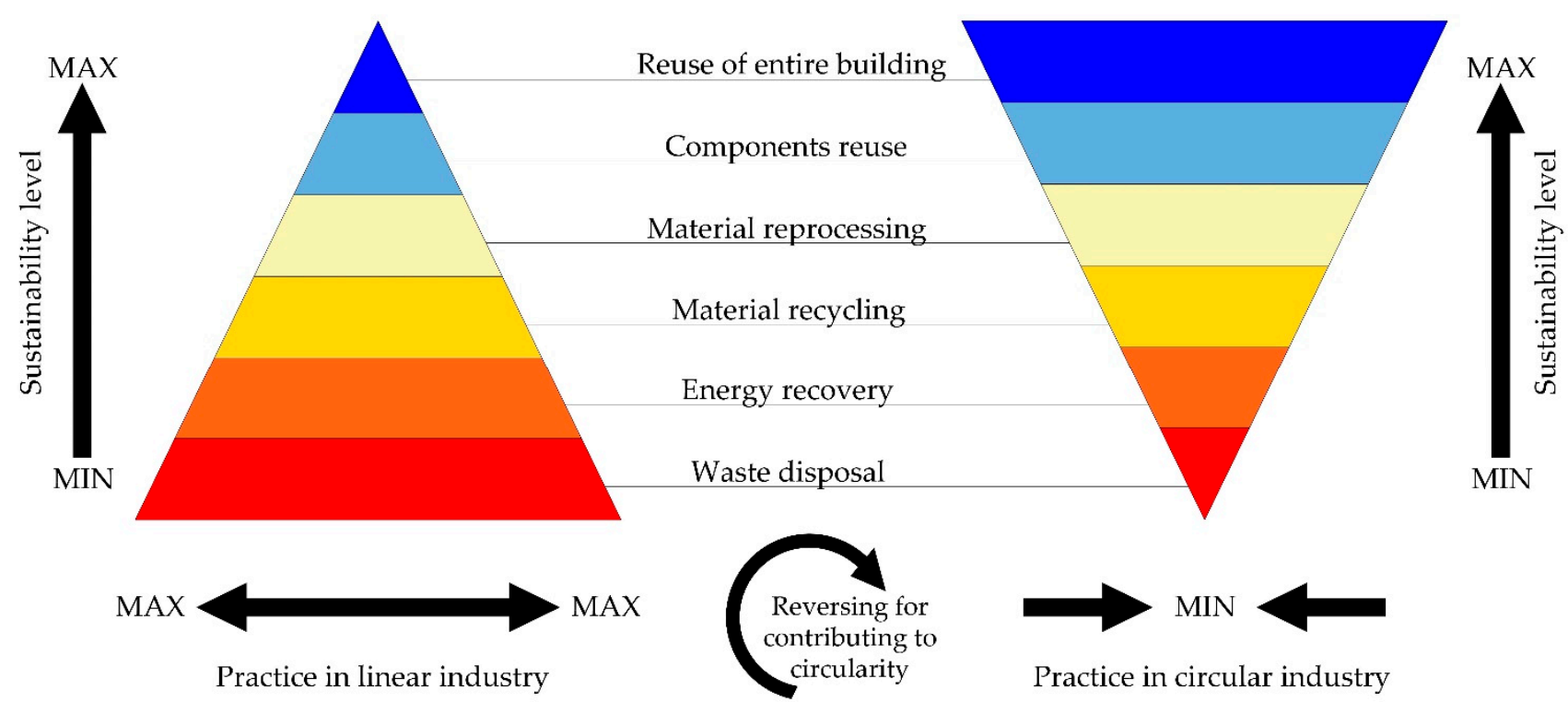

Figure 3. Sustainable hierarchy of end-of-life practices of a building (drawing by G.B.).

\subsection{Structural and Non-Structural Deconstruction}

Deconstruction as alternative to demolition plays an important part in the achievement of a sustainable building circularity, allowing the reduction of waste destined for disposal, the reuse of building components for new lifecycles, and better recycling options deriving from the selective dismantling. It seems obvious that in order to deconstruct a building and then break it down from a single aggregate to a multitude of elements of different materials that are connected to each other in various ways, it is necessary to be fully aware of its 
internal composition. Knowing the inside of a building means, first of all, to understand its construction system, namely the part expressly intended to absorb the loads and external actions to which the building is subjected during its operational life, and its construction techniques, namely the presence of some functional and dimensional characteristics strictly related to the connection between building components. Therefore, a structural system is composed of a series of elements connected to each other in various ways according to the construction techniques. On a smaller level of detail, an object can be defined as a "structure" when, to ensure the pre-established performance levels during its lifecycle, it is destined to be subject to a system of forces in balance with each other and applied at different points [54]. A "structural element" is defined as a portion of said body whose real behavior is generally expressed through characteristic formulas of a simple model [54]. Structural elements are used in structural analysis to split a complex structure into simple elements, because within a structure, an element cannot be decomposed into parts of different kinds (e.g., beams, pillars, foundations) [55]. Therefore, the structural elements (named also "load-bearing") are the parts of the building specifically designed to absorb the loads and external actions to which the building is subjected during its entire operating life. They are distinguished from the "non-structural elements" that do not carry loads and often only have a dividing and complementary function (e.g., partitions, closures, openings, technical installations) [55].

The structural elements include the foundation structures, namely the part of the building that takes the loads of the elevated structures to transmit them to the ground anchoring the building to it, and the structures in elevation (vertical, horizontal, and inclined), namely those having the function of supporting the loads of the building system and of statically connecting its parts [56]. Non-structural elements can be organized according to their function. (1) The building envelope has the function of separating and conforming the internal spaces of the building system with respect to the outside with the purpose of protection from the direct action of atmospheric agents. They can be disposed vertically (such as infill walls and windows) or horizontally (such as roofs and skylights). (2) The function of partitions is to divide and shape the internal spaces of the building system. Vertical (partition walls, doors, and protection elements), horizontal (floors, mezzanines, frames), and inclined (stairs and ramps) partitions are distinguished. (3) Finishes have the function of completing the external and internal spaces (floor tiles, walls coatings, and plastering). (4) Technical systems allow the use of energy and sanitary flows (electrical, heating and air conditioning, sanitary, disposal, fire prevention systems, etc.) [56]. In the following Table 3, structural and non-structural elements have been listed according to their specific functions.

Table 3. Building's structural and non-structural elements.

\begin{tabular}{|c|c|c|c|}
\hline Element Types & Building's Part & Types & Constructive Element \\
\hline \multirow{12}{*}{$\begin{array}{l}\text { Structural } \\
\text { elements }\end{array}$} & \multirow{6}{*}{$\begin{array}{l}\text { Foundation } \\
\text { structure }\end{array}$} & \multirow{4}{*}{ Shallow } & Masonry foundation \\
\hline & & & Foundation beams \\
\hline & & & Foundation slab \\
\hline & & & Foundation plinths \\
\hline & & \multirow{2}{*}{ Deep } & Piles \\
\hline & & & Monopiles \\
\hline & \multirow{6}{*}{$\begin{array}{l}\text { Elevation } \\
\text { structures }\end{array}$} & \multirow{2}{*}{ Vertical } & Load-bearing walls \\
\hline & & & Rigid frame \\
\hline & & \multirow{2}{*}{ Horizontal } & Vaults \\
\hline & & & Slabs \\
\hline & & \multirow{2}{*}{ Inclined } & Stairs \\
\hline & & & Ramps \\
\hline
\end{tabular}


Table 3. Cont.

\begin{tabular}{|c|c|c|c|}
\hline Element Types & Building's Part & Types & Constructive Element \\
\hline \multirow{18}{*}{$\begin{array}{l}\text { Non-structural } \\
\text { elements }\end{array}$} & \multirow{4}{*}{$\begin{array}{l}\text { Building } \\
\text { envelope }\end{array}$} & \multirow{2}{*}{ Vertical } & Infill walls \\
\hline & & & Doors and windows \\
\hline & & \multirow{2}{*}{ Horizontal } & Roofs \\
\hline & & & Skylights \\
\hline & \multirow{5}{*}{ Partitions } & \multirow{3}{*}{ Vertical } & Partition walls \\
\hline & & & Doors \\
\hline & & & Parapet and railing \\
\hline & & \multirow{2}{*}{ Horizontal } & Countertops \\
\hline & & & Mezzanines \\
\hline & \multirow{4}{*}{ Finishing } & \multirow{2}{*}{ Indoor } & Floors \\
\hline & & & Coatings \\
\hline & & \multirow{2}{*}{ Outdoor } & Floors \\
\hline & & & Coatings \\
\hline & \multirow{5}{*}{\multicolumn{2}{|c|}{ Technical installations }} & Sanitary systems \\
\hline & & & Thermal systems \\
\hline & & & Air conditioning systems \\
\hline & & & Electrical systems \\
\hline & & & Fire prevention systems \\
\hline
\end{tabular}

Depending on the construction system, the categorization made above may vary slightly: for example, an elevated structure can have both load-bearing and closing values, just as a floor can be structurally collaborative or completed carried by other structural elements. Therefore, having a better idea about the deconstruction possibilities is needed to analyze the most common types of structures (or constructive systems) and to analyze their own degree of deconstructability, making a distinction between non-structural and structural elements.

\subsection{Building's Constructive Systems}

The constructive system of a building is the set of devices designed to transfer the loads deriving from its use and own weight to the ground, acting as a physical unitary entity formed by elements but in which the character of the whole dominates the relationship between the parts [56]. Compared to what has already been mentioned in the previous chapter, it can be said that the constructive system corresponds to the set of all structural elements intended to carry loads and resist external actions. The spatial organization of the different constructive systems is based on three elementary principles: trilith, arch, and rope. Then, the development of construction technologies has produced in parallel the tendency to a progressive reduction of the weight of the structures and therefore to an improvement of the static efficiency [57]. The trilith consists of two vertical elements, the piers, and a horizontal element, the "jack arc" or "architrave", which serves to support the loads above and to transmit them to the piers; this static system is based on the transmission of forces acting vertically with the exception of all horizontal ones, as the architrave is stressed by bending while the piers are stressed by compression. The arch is a structural element with a curved shape that is usually suspended, consisting of many stone or bricks elements in series, which are supported by mutual contrast and unload a force with an inclined line of action on two piers. Unlike the trilith, the arch is a "pushing" structure, since it generates lateral thrusts (so even horizontally), and this has the advantage of a more efficient distribution of the loads due to weight, allowing the opening of much wider spans. Finally, the rope is a cable made up of a set of threads (of various materials but nowadays typically metallic or textile fiber) tightly wound in the shape of a spiral. 
The principle of the rope is based on the tensile strength, namely the resistance to stresses occurring along the same axis as the rope [57].

The trilith is the basis of three-dimensional structures such as load-bearing walls buildings. The arch is the basis for the realization of vaults. The application of the principles of the arch to the trilithic system leads to the definition of the rigid frame construction system, where the piers and the architrave are kept together by the nodes, which are joints that prevent rotations. In this way, the architrave has less bending stress in the middle, while the piers absorb, in addition to the compressive forces, also those of bending caused by the joint constraint. The rope, on the other hand, is the basis of "pre-stressing", which is a technique that consists of artificially producing a tension in a structure made in a factory and then mounted on site, with the aim of improving its tensile strength and obtaining components that are light but capable of covering great distances [56-58]. The following Figure 4 shows the criteria that lead to the conception of the building construction systems, as well as the distribution of the loads (red lines) through the elements and the building components.

It is evident how the choice of the static scheme influences the characteristics of the structural components of the building and how the definition of this scheme is directly connected to the types of connections that exist between vertical and horizontal elements and those between the structural and non-structural ones.

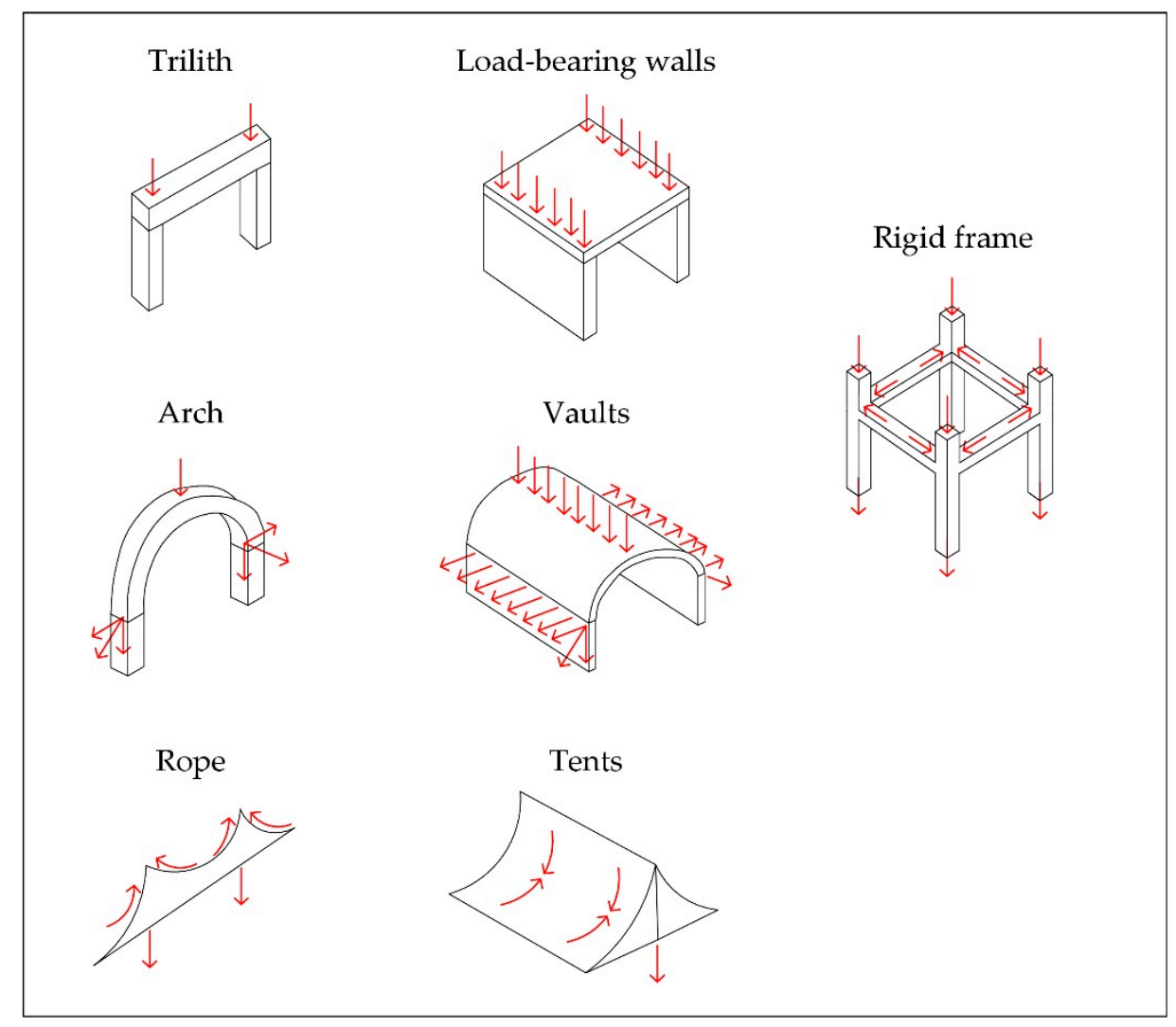

Figure 4. Building constructive systems structural criteria (drawing by G.B.).

\subsubsection{Load-Bearing Walls Buildings}

"Load-bearing walls" is a constructive system where the walls hold the weight of the elements above and transfer the load to the ground. A building of this type can be defined as a three-dimensional assembly of walls and slabs characterized by a "box-like" system that gives the overall stability and strength where all the elements cooperate in resisting the applied loads [59]. A load-bearing walls building is a complex structure in which all vertical and horizontal elements cooperate in resisting the applied loads: the walls bear the load of the elements above them, conducting their weight to a foundation structure and from it to 
the ground; the slabs are carried by the walls and must be rigid and resistant enough to distribute the loads between the structural walls [57]. It is one of the oldest construction methods, having its roots in the Roman world [60]. The Roman construction tradition has elaborated a great variety of ways of building the walls, the so-called "opus" (Latin word that means "work" or "opera"), with construction techniques that varied considerably over time and were often adapted in different places according to the most readily available building materials. In particular, a fundamental step in this excursus happened at the beginning of the 2nd century B.C., with the invention of the opus caementicium, the Roman concrete, namely a masonry consisting of a mortar mixed with stones, with the mortar in turn consisting of lime mixed with sand or pozzolan [61]. This construction system was the main construction method for buildings for centuries, until the advent of reinforced concrete technology at the end of the 19th century. Before then, in buildings, every wall could be considered load-bearing, and only the advent of the structural frame type led to the definition of non-load-bearing walls with the complementary function of separation from the outside or internal partition [56].

Load-bearing walls can be made of different materials: building stone such as granite and limestone, clay bricks, concrete blocks, adobe, blocks of expanded clay, or cellular concrete, and they can be integrated with the insertion of steel reinforcing bars in the hollow sections of the brick. There are also reinforced concrete walls that can be directly cast on site using wooden formworks, which define the external geometries of the wall, in which first, the steel bars are housed, and then, the liquid concrete is cast. The wooden formworks are removed after twenty-eight days, which is the amount of time necessary for the concrete to harden and acquire full mechanical properties [62] and therefore be able to support the weight of the other structures to be built above it. Bricks and blocks are usually bonded together by binders, namely substances with adhesive and cohesive properties which, when mixed with other materials, give rise to a plastic mass and which, over time, undergoes a progressive stiffening process until reaching a high resistance [56]. The most used in construction are lime, mortar, and cement. To create openings in load-bearing walls, architraves and jack arches are often used. These are structural elements used to create openings in the walls and positioned at the top of doors and windows. They are not very large in size and discharge the weight of the walls above toward the sides of the compartment. Partition walls are usually made of bricks, gypsum, or plasterboard. They have the exclusive function of separating internal spaces and do not have a structural function [58].

Regarding foundations, before the advent of concrete, they were made of stone or appeared as an enlargement of the cross-section of the wall: in practice, it was a real wall with a larger section than the load-bearing one [58]. Today, however, load-bearing walls are commonly built on reinforced concrete or pre-stressed concrete foundations.

Among the various types of floors used for this construction system, the most common is the reinforced concrete and hollow bricks mixed floor type, consisting of a combination of reinforced concrete beams (made on site with the use of reinforcing steel bars) with mainly resistive-structural functions, and light elements, normally in brick or expanded polystyrene (EPS), with the role of formwork between the beams. The floor is completed with a concrete casting to form, above the lightening element, a concrete slab with a steel reinforcing bar grid, which has the function of distributing the load [58]. Wooden floors are also common: they are characterized by a framework of main wooden beams, rough or squared, arranged parallel with a distance of $50-100 \mathrm{~cm}$, a secondary framework formed by connecting and stiffening wooden elements that rested on the beams, and a complementary structure, a concrete screed of $5-6 \mathrm{~cm}$ or a plank of large boards nailed on the aforementioned rafters, which is made in order to hold the secondary elements in place and make the structure rigid [58]. There is also a great variety of iron and steel floors, which are characterized by the most various local building traditions, where the main frame is composed of metal sections, the secondary frame is composed of light materials such as bricks or corrugated sheet, and it is always completed by a concrete screed [58]. 
The roofs can be flat, with characteristics similar to those described for floors, or pitched, using a "truss", which is a structural element traditionally made of wood, formed by a flat reticular frame that is vertically placed. Due to its triangular structure in which the horizontal element eliminates the thrusts of the inclined ones, the truss allows the loads to be effectively unloaded on the load-bearing walls, also through a crowning curb of the wall made of concrete, which provides additional rigidity to the building [58]. The following Figure 5 shows the composition of a load-bearing walls building, with the differentiation of its components by color according to their function.

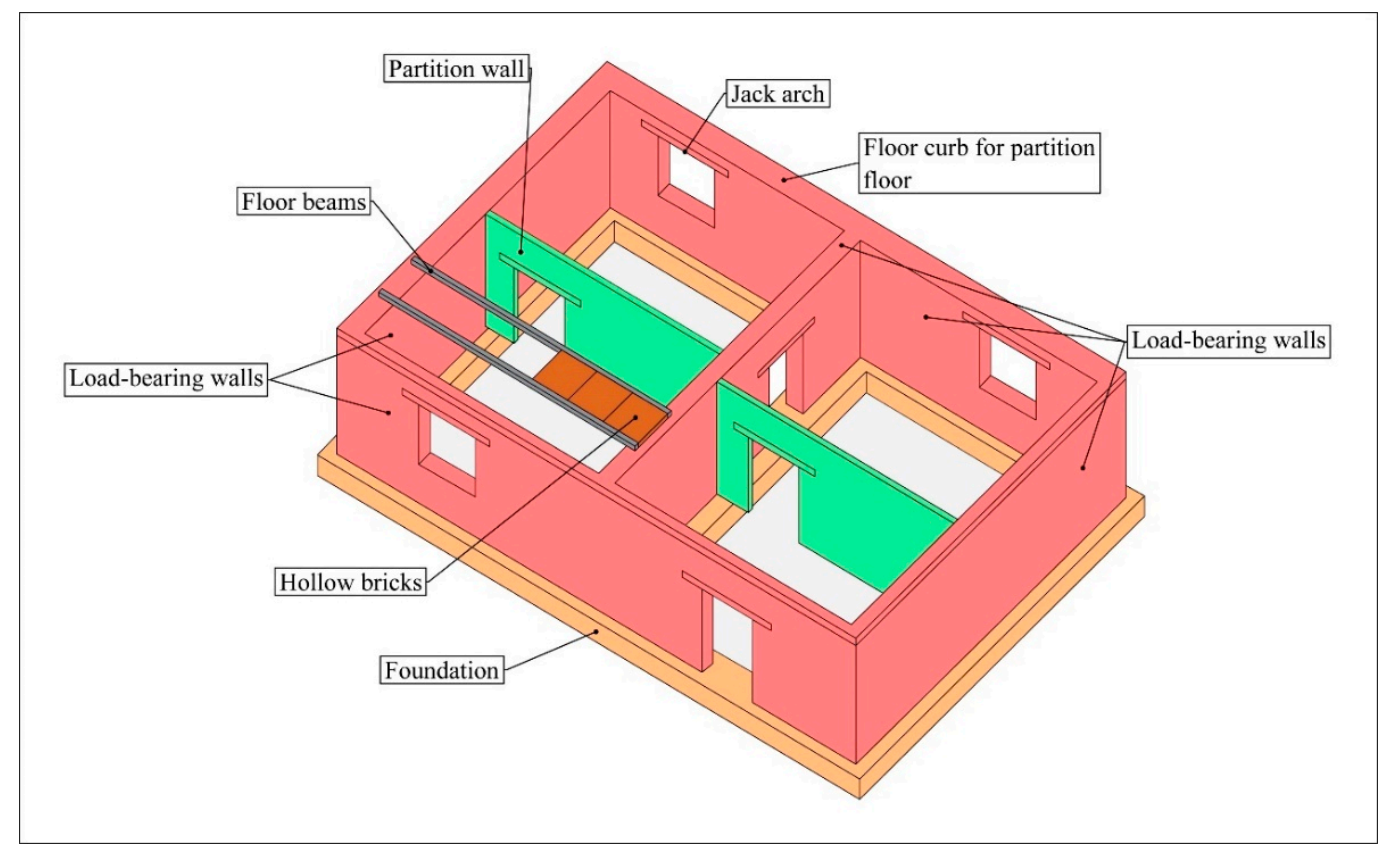

Figure 5. Load-bearing walls building scheme (drawing by G.B.).

\subsubsection{Rigid Frame Buildings}

The load-bearing walls represent a significant constraint for the building, preventing the free articulation of the system and affecting the maximum widths of the openings of the rooms and windows [56]. Therefore, the genesis of the constructive system in rigid frame can be traced back to the reduction of the sections of the vertical bearing elements that give rise to the pillars and to the increase in the spans of the architraves that are transformed into beams [58].

Rigid frame buildings are structures consisting of horizontal (beams) and vertical (pillars) elements with the task of supporting the weight of the building and unloading it on the ground. Usually, the loads are placed directly from the slabs to the beams, which are inflected under their action; the loads are transferred to the beams' ends and distributed between the pillars, which have the task of passing them to the foundations and from there to the ground [57]. Therefore, in rigid frame buildings, there is a system of rigid rods that can assume vertical, horizontal, and inclined positions. All the rods must withstand the stress of compression, bending, and shear: therefore, for the rigid frame construction system, from a material point of view, wood, steel, normal, and prestressed reinforced concrete are particularly favorable. The connections between rigid rods, the so-called "nodes", can be realized with different techniques, dry or wet (intended as without or with the use of binders). In the case of structures in reinforced concrete cast on site, the nodes are similar to "joints", giving the interpenetration of beams and pillars and allowing them to resist horizontal thrusts. It happens because of the use of concrete as binder, which, once hardened, creates a monolithic connection [62]. In the case of steel, wood, or prestressed concrete frames, on the other hand, connections can be realized also with dry techniques and a minimal use of binders, and the nodes have a behavior more near 
to "imperfect hinges" or "weak joints" [54]. Sometimes, rigid frame buildings could not have the ability to withstand horizontal actions (wind, earthquake) and must be integrated with a frame bracing system, namely stiffening elements arranged in the two orthogonal directions, which are provided to give the building better rigidity [63]. Wooden frames nodes can be realized by nailing, interlocking, or bonding. Prestressed concrete frames could be made by components interlocking themselves or realized with the addition of small quantities of binders. Finally, steel frames are usually made by welding-a process that allows the physical-chemical union of two metal elements by melting them, creating a permanent connection - and bolting, which is a procedure for connecting the components of a structure through the application of bolts that are also removable [57].

As for the foundations, the most used type are the plinths, parallelepiped-shaped reinforced concrete blocks, with a square or rectangular base, which act as a base for each pillar of the structure with the purpose of transmitting the loads to the ground. They can be built on site or prefabricated and, usually in seismic risk areas, they are connected to each other with connecting beams that give rigidity and have a stress absorption function [64]. When the mesh of the frame is too dense and the pillars would be too close for the realization of the plinths or if a greater bearing capacity is required to transmit the loads to the ground, different types of foundations are chosen: foundations beams, with the same functions mentioned above when they serve as connections for plinths, or foundations slabs, namely a reinforced concrete slab that affects the entire foundation area of the building, stiffened by a series of beams connected to the pillars of the upper structure [64]. When the most suitable laying surface is not reachable with a convenient excavation, as well as whenever it is impossible to adopt only an ordinary superficial foundation, integrated foundation piles are used. The foundation piles transmit to the ground a non-negligible part of the vertical load of the foundation, both by friction along the lateral surface and by supporting the base of the pile. The advantage is that of reducing long-term settlements by exploiting the resistance of deep and adequately load-bearing layers of soil [65].

Among the various types of floor used for this construction system, the most common are the reinforced concrete and hollow bricks mixed floor and the so-called "Predalles" floor, which is a prefabricated slab consisting of modular elements in reinforced concrete with steel mesh and polystyrene blocks-particularly suitable in the need to cover high spans or when particular overload requirements must be met [58].

Since the structural function is ensured by the structural frame, in this construction type, the walls have only a closure and separation function between the internal and external space. The infill walls fill the squares of the external frames and have particular importance for determining the performance in the use of a building, guaranteeing thermal and acoustic protection of the internal spaces [56]. In the most applied type, the infill was essentially composed of a double layer of perforated bricks separated by a non-ventilated air gap, but nowadays, there is a large variety of types that include the insulation layers, too. Partition walls, on the other hand, serve to separate the interior spaces and are generally made up of elements of limited thickness, so they can be easily moved or removed; until a few decades ago, partitions were made exclusively with perforated bricks, which are light, resistant, and easy to produce and assemble; today, there are many more solutions, such as lightened concrete or plasterboard partitions and prefabricated sandwich panels [56]. Figure 6 below shows the composition of a rigid frame building, with the differentiation of its components by color according to their function. 


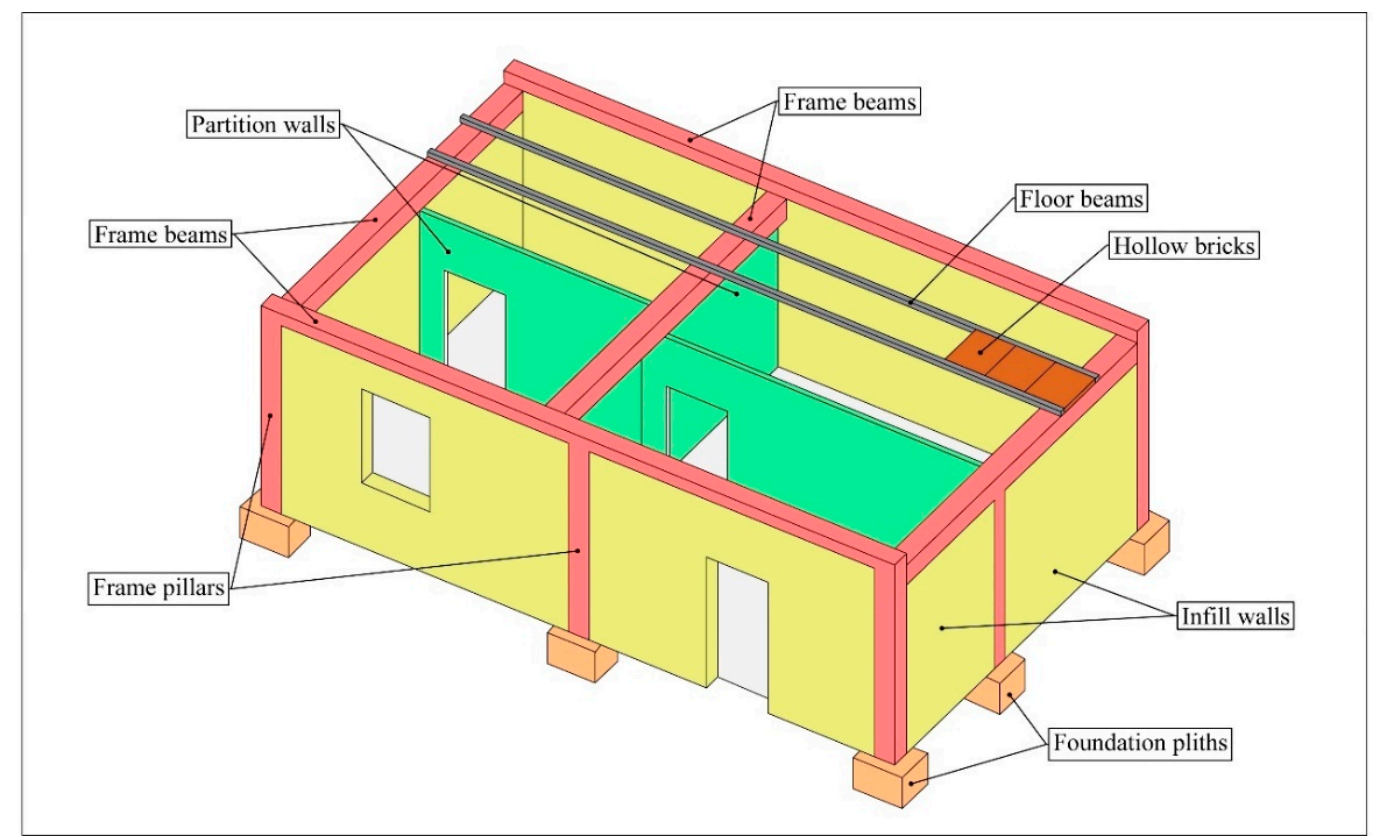

Figure 6. Rigid frame building scheme (drawing by G.B.).

\subsubsection{Prefabricated Components}

Prefabrication in buildings is the production process of components made off site and subsequently deposited in a warehouse, transported to the construction site, and assembled on site with codified procedures to form a building [66]. The most widely used types of prefabricated components in the construction sector are prefabricated concrete panels and steel prefabricated beams (in structures where a particular shape is repeated many times). However, there are also components made of aluminum, wood, plastics, and other high-strength materials [67] that are prefabricated. As for concrete systems being made in a factory, the control over the preparation of the mixture is usually better, the pouring takes place in reusable molds (and not in a disposable wooden formwork, as in the construction site), and the concrete can be mixed without having to be transported and wet pumped on site [68]. The prefabrication of steel profiles reduces the costs of cutting and welding on site as well as the associated risks [69]. Laminated timber, made through a technological process of pressure gluing of wooden boards already classified for structural use, reduces the defects of solid wood and allows producing elements of variable shape and size [70].

Prefabricated elements can differ in the geometry of the basic elements: linear, as beams and pillars; shape, as panels for façade and floor elements; and three-dimensional, as complete spatial units, rooms, and stairs. The connections between elements are usually made by dry techniques, such as bolting, interlocking, traps, and sealing materials, and sometimes by wet ones, with concrete casting for completion on site [71]. The prefabrication of modular elements also allows the realization of complete building components, for example reinforced concrete panels already coated with thermal insulation or with components for windows and doors [67]. The big difference between buildings fully built on site and the ones made out of prefabricated components lies in the connection joints between beam-pillar and slab-beam: in the first case, the joints make a homogeneous structure, while in the second, joints are points of discontinuity due to the presence of elements supporting each other with wet or dry connections [56].

Starting from the 1950s, prefabrication was developed mainly for the construction of industrial buildings, but thanks also to the great demand on the market, this type of construction has spread more widely. In fact, with the advent of lighter materials, the use of prestressing and the improvement of the construction process in the plant, preconstruction elements have also been developed for sheds, trussed and arched structures, containers, tents, and large buildings such as residential settlements with repeated hous- 
ing units, office buildings, and single-family homes [72]. Among the reasons for this widespread diffusion, the main advantages are as follows: (1) high construction speed, due to the almost total absence of cast-in elements of reinforced concrete; (2) reduced number of personnel required in the plant and on site; (3) better control of the quality of materials and elements, as they are made in the factory with industrialized processes and better durability; (4) adaptability of the elements, which can be used for the construction of buildings with different intended uses (industrial, commercial, agricultural, tertiary, residential); (5) chance of using the post-compression technique to obtain structural continuity between different elements; (6) speed and cost-effectiveness of the process [66].

Due to properties such as modularity, flexible light-weight technologies, fast and easy assembly, and dry-connection procedures, this construction technique is also frequently used for temporary housing and pop-up environments, which are intended as structures conceived from the outset as temporary and adaptable to different uses and needs even in case of emergency [21], scoring a high deconstruction potential when well planned in the design phase [73]. The following Figure 7 shows a general construction scheme of buildings made of prefabricated components, distinguishing them by color according to their function.

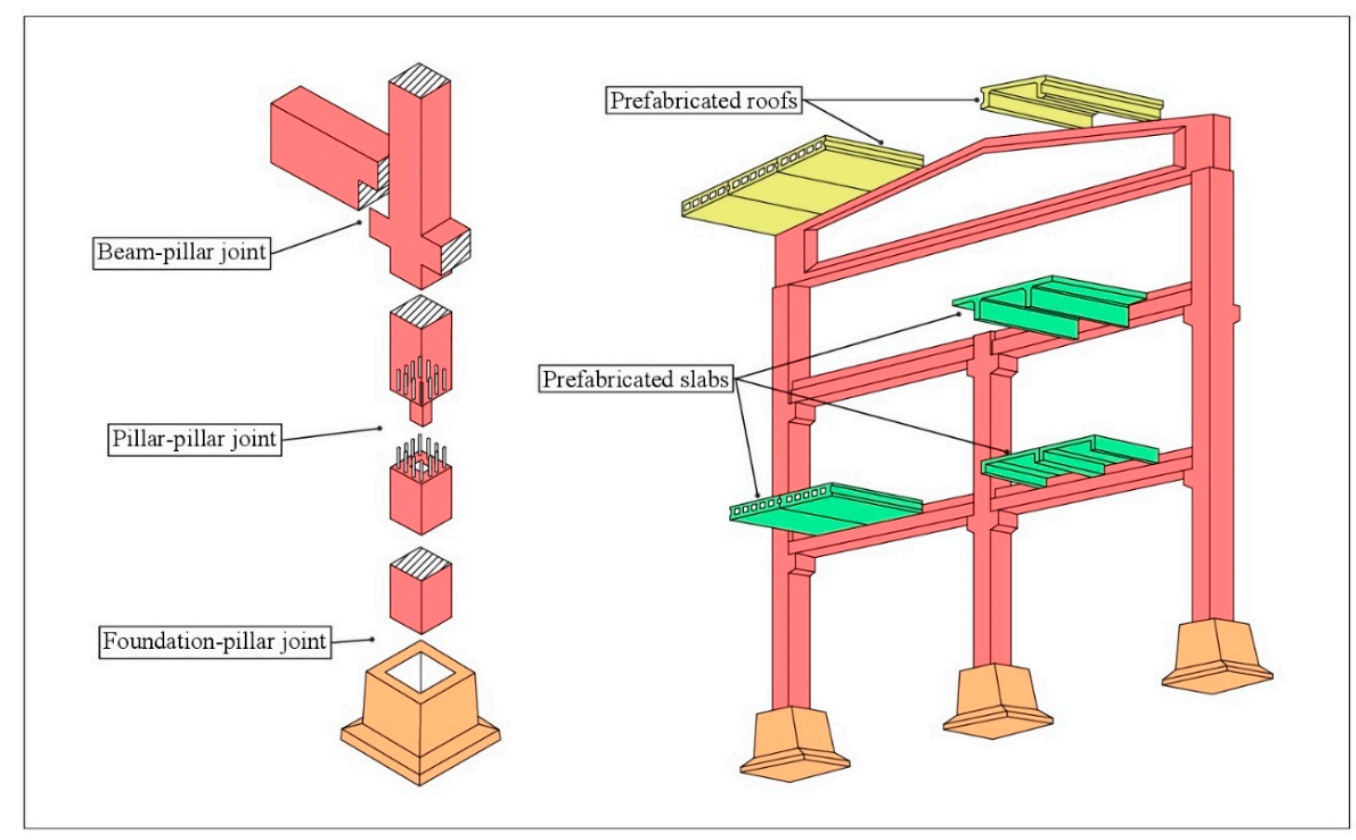

Figure 7. Buildings made of prefabricated components scheme (drawing by G.B.).

\subsection{Real-Life Examples}

Following the definition of the main constructive systems, some real-life examples that have a potentially positive impact on the environment, due to the application of deconstruction strategies and techniques, are highlighted. In the context of this research, an "example" corresponds to a building whose construction and deconstruction took place according to the principles of sustainability, both in regard to the consequent reuse and recycling of deconstructed components and materials, and from the environmental point of view, related to the reduction of waste destined for landfills and the greenhouse emissions emitted during the lifecycle. Below, some real-life examples have been presented to show how the deconstruction potential can help to create more sustainable buildings and lead to better deconstruction outcomes.

Chartwell School is a building in Seaside, California that was designed to be adaptable and demountable, and it is an interesting example regarding the choices made in the design phase to allow the building to be efficiently deconstructable. For the structural wooden frame, larger wood modules were preferred to the most common modules on the market in order to have a lower number of pieces. In the end, this resulted in a $30 \%$ saving of 
construction timber compared to a conventional approach [74]. To simplify the connections and assembly of the roof, prefabricated structural insulating panels were chosen that are connected by bolting and therefore can be easily removed and reused. The wall covering has been fixed with a double-fold clip system since the use of bolting has been excluded due to the possibility that in the future it could be painted and that the paint would make the screws difficult to remove. Finally, the designers, in order to increase the deconstruction efficiency, have created a digital library that includes all the information necessary for the deconstruction of the building elements at the end of the lifecycle. They have also marked the structural pieces in a permanent way for easier identification [74].

The "Whole House Reuse" (WHR) is a project realized in Christchurch, New Zealand, with the aim to recover and reuse materials from a residential home and to create new products using the recovered materials. In addition, the organization of exhibitions for the local public to promote awareness of the conservation of resources and sustainable deconstruction practices has been foreseen. Following the devastating earthquake that affected New Zealand in 2011, which resulted in 10.000 homes being declared unfit for occupation and requiring demolition, the WHR project started within the context of post-earthquake response as a sustainable answer to the destructive demolition and wastage [75]. As such, the project celebrates a thoughtful and resourceful alternative and demonstrates the careful nature of deconstruction, which enables high-quality products to be upcycled from salvaged resources. The house selected for the deconstruction was carefully dismantled part by part by an interdisciplinary team of professional workers and volunteers. The recovered elements were identified, classified, quantified, catalogued and suitably archived in preparation for the reuse phase of the project. The mentioned items were carefully categorized based on a physical assessment of the quality of the harvested materials and level of reusability, reparability, and recyclability. The WHR project allowed the recycling and reuse of about twelve tons of recyclable materials collected from the building in question, materials that, in the absence of the application of deconstruction practices, would probably have ended up in landfills. The study estimates that recovered materials could potentially save around 502.158 MJ of incorporated energy and prevent carbon emissions of around $27.029 \mathrm{~kg}\left(\mathrm{CO}_{2} \mathrm{e}\right)$ [75]. Projecting this estimation in a scenario in which all 10.000 houses damaged during the earthquake were deconstructed for the reuse of material rather than with conventional demolition, it would have been possible to save a total of 5.021.580 GJ of energy and 270.290 tons of carbon emissions. The study also indicated that the deconstruction and reuse of material may not be completely economically viable in current market conditions, but it contributes more to socio-economic and environmental aspects, with significant advantages compared to conventional disposal-demolition [75].

"Passivhaus" is a low energy design standard developed in the 1990s in Germany by the Passivhaus Institut [76], providing year-round comfort without significant active space heating or cooling systems with the use of only a minimal source of electrical energy. It is called "passive" because the sum of the passive contributions of heat from solar radiation transmitted by the windows and the heat generated inside the building (by household appliances and by the occupants themselves) are almost sufficient to compensate for the thermal losses of the walls during the cold season [77]. A Passivhaus system for two-three bed houses used in Scotland presents also an interesting example concerning deconstructability. In this project, the deconstruction principles were already incorporated into the project, from the beginning of the design phase. The buildings were composed of insulated-wall-panels that use mechanical fixings and screws to form fully insulated timber stud walls. Oriented strand board (OSB) boards form the sandwich, and the joints are sealed using airtight barrier tapes with the internal vapor control barrier stapled to the OSB boards. The wall panels are nailed to timber load-bearing sole plates, which in turn are nailed into a masonry sub-structure. The roof is made of cassette panels glued to timber rafters and glulam ridge beams. The flooring is tongue and groove solid timber boards, and it is glued to the base structure. In this example, the deconstruction principles considered in the design phase allow easy deconstruction operations. The upper floor, internal walls, 
windows, doors, and floor finishes can all be dismantled with standard equipment. The ground floor and foundations can also be dismantled using non-specialized equipment once the external and internal walls have been removed. Several materials used, such as the mineral wool, OSB boards, fiber cement slates, and insulation have been recycled or re-used in a new context, in some cases after a cleaning [78].

The "Circl Pavillion" in Amsterdam, designed by architect Hans Hammink of the Architekten Cie [79], is another example of circular and deconstructable building, in which components are continually reused and waste is avoided. The interior space has been designed to be as flexible as possible and to be dismantled with the use of movable walls made from recycled aluminum and expanded metal mesh. Then, the end-of-life recovery of the components which will be resold and used in other buildings. The insulation of walls and ceilings was made up of recycled jeans, consisting of $2.500 \mathrm{~kg}$ of material, sandwiched to provide an acoustic buffer. The windows frames were removed from demolished office buildings for being reused, and hardwood parquet flooring and an old glazing facade were taken from old buildings and used as internal wall partitions. The wooden structures are joined by hollows and bolts, so that at the end of life, the wooden beams can be dismantled and reused in a new structure or for a different use [79].

The examples presented show that it is possible to have positive results by properly deconstructing the building at the end of its lifecycle. Where these strategies have been carried out with foresight, planned already in the design phase, the effects produced on the urban environment have been concretely positive on several levels. It also appears that the deconstruction of buildings may lead to new types of material uses, presenting itself as a new model to contribute to the sustainability of the construction sector.

\section{Results}

Deconstruction needs to be separated into two categories, depending on the relation to structural or non-structural elements [80]. "Structural deconstruction" involves the dismantling of the structural building components that are an integral part of the building and contribute to its stability, such as beams and pillars for rigid frames and walls made by bricks for load-bearing systems. It needs a range of tools and equipment, heightened safety considerations, and a time frame of days or weeks to be realized. It is not always possible, depending on the construction technique whether it allows the connection between the elements in a reversible way or not [36]. "Non-structural deconstruction" consists in the recovery of non-structural components whose removal is not dependent on the structural integrity of the building and that are usually easy to dismount, such as doors, windows, and finishing materials. In general, non-structural deconstruction can be accomplished relatively easy and with few tools, limited labor, and typical job-site safety considerations, usually lasting hours or days. The building components can be removed without destructive approaches and additional structural support, such as bracing is usually not needed during the deconstruction operation [36]. Furthermore, the reuse of these elements is today considered a solid market [81]. Practical considerations and common sense suggest deconstructing the non-structural elements first, dismounting all the components such as appliances, windows, doors, and other finishing materials, which if removed do not cause the building to collapse. After the non-structural deconstruction, the structural one is the next step, and it is usually realized from top to bottom, starting from the removal of the roof to get to the foundations to avoid the collapse of the building.

The following Table 4 describes the main characteristics of these two deconstruction approaches, making a comparison between them and the related criteria for demolition. 
Table 4. Comparison between deconstruction and demolition.

\begin{tabular}{cccc}
\hline Criteria & Demolition & Non-Structural Deconstruction & Structural Deconstruction \\
\hline Definition & $\begin{array}{c}\text { Arbitrary destruction of building } \\
\text { in order to quickly clear the } \\
\text { construction site }\end{array}$ & $\begin{array}{c}\text { Removal of building components } \\
\text { not affecting the structural } \\
\text { integrity of the building }\end{array}$ & $\begin{array}{c}\text { Removal of building components } \\
\text { completely integrated in the } \\
\text { building and with structural } \\
\text { function }\end{array}$ \\
\hline Time & Few days & Few days & Days or weeks \\
\hline Costs & Low & Medium & High \\
\hline Equipment & $\begin{array}{c}\text { Expertise required for cranes, } \\
\text { excavators, and wrecking balls }\end{array}$ & $\begin{array}{c}\text { Simple tools required. Special } \\
\text { expertise is usually not required }\end{array}$ & $\begin{array}{c}\text { equipment required. Special } \\
\text { expertise could be required }\end{array}$ \\
\hline $\begin{array}{c}\text { Safety conditions } \\
\text { Degree of de- }\end{array}$ & High & Standard & High \\
\hline
\end{tabular}

The categorization in Figure 8 defines the different layers that make up the building and the related consecutive phases in which these must be deconstructed, regardless of the chosen building construction system. The first two layers consist of all the technical installations, such as wiring, plumbing, fire extinguishing systems, air conditioning, heating and ventilation systems, as well as and finishes such as fences, suspended ceilings and floor tiles. Many buildings are demolished early if their outdated systems are too entrenched to be easily replaced; therefore, a very flexible strategy is needed from the building's design stage in order to allow deconstruction at the building end of life. For example, the use of suspended ceilings, ensuring high spaces and that all installations are mounted in a visible way, allows both an easy inspection in homes, installations that need to be repaired or renewed, and an easy deconstruction of both the systems and the false ceilings. The third layer consists of all the partitions, the interior layout that includes partition walls, and internal doors. These building components can be also realized with dry connections, which make deconstruction activities easier and allow good results in terms of reuse of the building components. Sometimes, the connections are realized with binders, but their deconstruction can be quite easily accomplished, maybe not for reuse but for downcycling or recycling. The fourth layer consists of the enclosures, the building envelope-namely the facades and roofs of the building. As previously pointed out, the building shell can have a structural or non-structural function, depending on the building constructive system. However, there are parts, such as windows and doors, that are non-structural elements regardless of the type of building, and once deconstructed, they are easily reusable or recyclable. The fifth and sixth layers consist of the structural elements, in elevation and in foundation. Considering the huge existing building heritage, which has not been designed for deconstruction, it is clear that these layers are the most difficult to deconstruct and that demolition often appears to be the fastest and most obvious choice.

In the case of deconstructable buildings, namely buildings that have been designed to be completely deconstructed at their end of life, the structural deconstruction must take place from top to bottom - therefore from the roof to the foundations, so as to operate safely and avoid collapses of the structure. Once the building layers have been defined, it may be easier to consider deconstruction and resource reduction strategies during the design process. However, it is also necessary to analyze the differences that arise between the various construction systems to evaluate the degree of deconstruction effect that a building can have. 


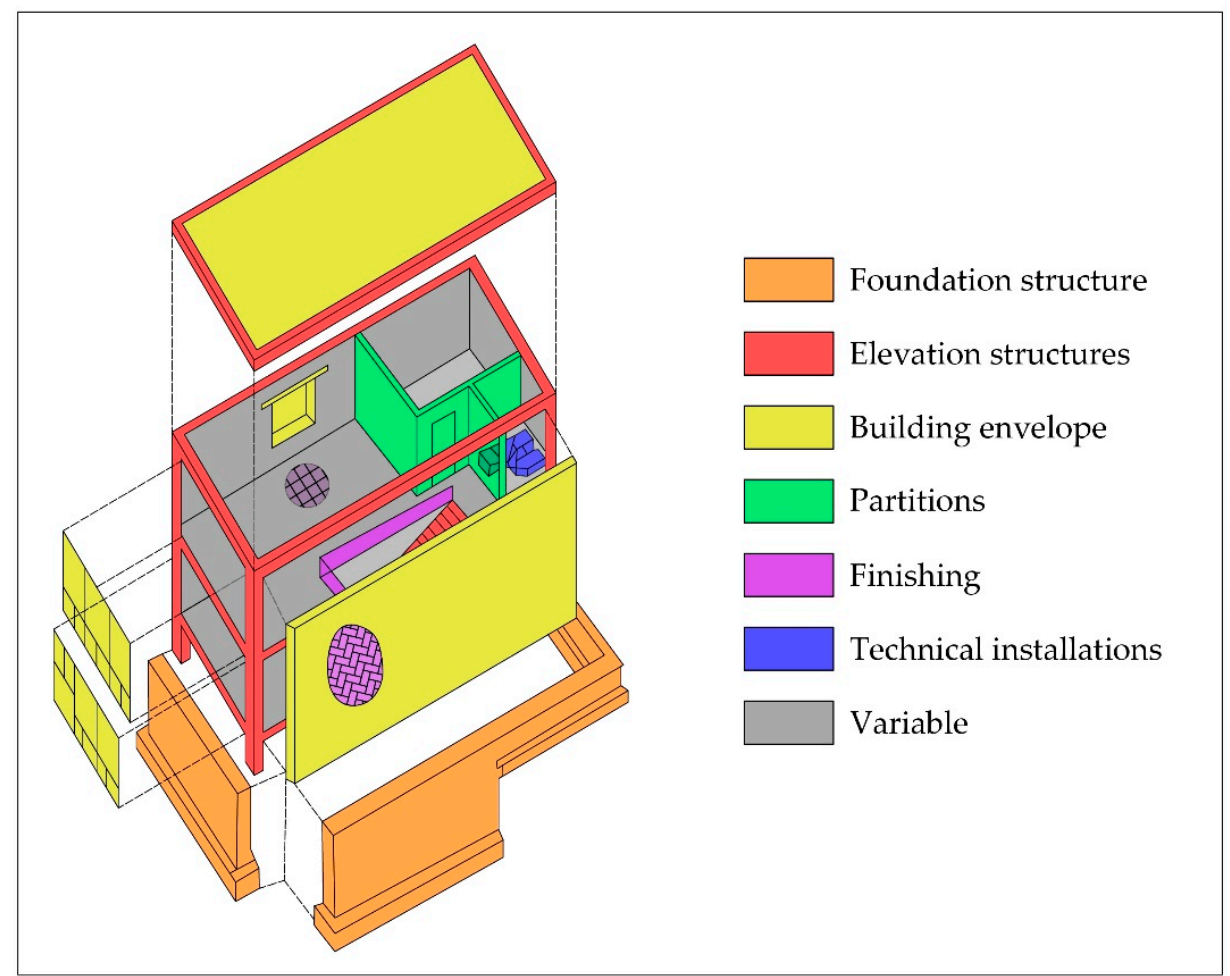

Figure 8. Building decomposition (drawing by G.B.).

Regarding load-bearing walls in buildings, most of these are made with bricks connected by wet binders such as mortar, lime, or cement. The use of binders to keep the building components united is an obvious obstacle to the deconstruction process, as it can lead to component breakage and the subsequent impossibility to reuse them [47], so they are more likely to end up in a landfill. A possible option to close the loop is recycling: bricks can be used as a secondary raw material after being shredded and employed in various construction activities, for example, for roadbeds [47], in a process of downcycling, as they lose some properties and quality in their second life [82]. However, the best option would be the reuse: load-bearing walls can be dismantled in bricks, and after the binder is removed, the bricks can be reused. However, dismantling a brick wall might increase the need for safety precautions, and removing the mortar can be difficult and time consuming. Attempts can be done to keep the value of the products and upcycle them into new building products, such as new bricks and tiles, but this would not necessarily be economically feasible, involving bricks cleaning and smoothing treatments [47], and in many cases, these bricks cannot be reused as structural elements [12]. To avoid this situation, bricks can already be designed to be easily disassembled and reused. A good example for such a design is the dry-stack bricks [83]. A load-bearing wall made by dry-stack bricks consists of clay or concrete interlocking blocks that are laid dry-stacked or with minimum mortar slurry in a stretcher bond in a wall. Sometimes, the binder to join the bricks is replaced by plastic or metal units, with the same result to make the bricks easy to separate and reuse. This approach decreases the environmental impact of the bricks, because it extends their lifecycle and reduces the need for new products, but to make this possible, the end-of-life scenario needs to already be considered when the bricks are designed and manufactured to fit this system. Another advantage deriving from the use of these materials is the reduction of the construction time, as it avoids the mixing and laying of the mortar, and there is a reduced need for skilled labor. It is estimated that the combined effect of less skilled labor and increased production will reduce labor costs by up to $80 \%$ [83].

Regarding rigid frame buildings, here, the degree of deconstructability depends predominantly on the type of materials used and of connections (joints) between the structural elements, whether they are made with dry and wet techniques. In the case of wooden- 
and steel-framed buildings, the joints are mostly made of dry systems. For wooden-frame buildings, nailing and interlocking allow a fair degree of deconstruction and good chance for material reuse secondly and recycling. The same can be said for pre-stressed concrete frames, which are factory made to be modular and mountable to each other, with minimal use of a binder. For steel-frame buildings, joints are usually made by welding and bolting. Although welding is an economic process, it involves the emission of large quantities of greenhouse gases due to the melting of metals. Furthermore, welding creates a connection between the metal elements that can no longer be separated (or deconstructed) without damage or the aid of professional tools such as disc grinders [63]. On the other hand, bolting is a sustainable process, as the connection is dry, and the use of bolts that can be easily disassembled for the recovery and reuse of the rigid rods, which allows a good degree of deconstruction to the structure [84]. Finally, the most common rigid frame structures are those in reinforced concrete cast on site, whose nodes are continuous monolithic elements; namely, beams and pillars are fully integrated into each other. The possibility to efficiently deconstruct this kind of building drops drastically due to the presence of the cement that does not allow the deconstruction of the node for components reuse [85]. However, especially if the dismounting takes place in a not randomly destructive but targeted and localized way, the recycling of the components of reinforced concrete is still possible. For example, the metal bars obtained could be partially straightened, packaged, and sold, or, like almost all metal products, they can be recycled as scrap and then combined with other steel products, cast, and reformed [86]. In addition, crushed structural concrete may be re-used for the realization of new binders, although with full treatment and a designed mix, it may be possible to achieve even a structural grade concrete [82].

Buildings made of prefabricated components generally have a high degree of deconstruction in comparison with the constructive systems made on-site, which is mostly due to their "intrinsic nature". The prefabricated components are manufactured in the factory with industrialized processes that ensure their quality and are designed, both for economic convenience and from the point of view of attractiveness on the building market, to be assembled quickly and easily. Therefore, they are designed in a modular way and to be adaptable to different uses; for this reason, they are often connected with dry assembly methods, without involving (or minimizing) the use of binders, which require a certain amount of time to harden and acquire adequate mechanical resistance properties [72]. Once on site, the prefabricated components are immediately ready for assembly. The use of reversible assembly techniques (such as bolting for the connections of structural nodes of structural steel or timber profiles or the interlocking of a reinforced concrete pillar in a prefabricated plinth) and modular components that allow the reciprocal interlocking and the structural collaboration (such as the reinforced concrete panels of facades and floors) allow the construction of the building to be completed more quickly, due to the absence of binders, and with the help of a reduced number of laborers and machinery [69]. The structural elements are often designed to host non-structural elements, such as floors and internal partitions, which can also be integrated with finishing elements (plaster, cladding, flooring) or thermal and acoustic insulation, as well as facade walls that already have the housing for doors and windows [72].

It is evident that buildings made of prefabricated components generally present a high degree of deconstruction ability, since, at the end of their lifecycle, they often do not need to be demolished but rather need to be processed with a "construction-on-reverse" strategy that goes step by step, starting from the non-structural elements up to the structural ones. The relative ease and speed of disassembly allows many "second-life" options regarding reuse and recycling: doors and windows can be disassembled at low risk of damage and sold in the second-hand market [87]; the ceiling and facade panels can be dismantled and stored until a possible subsequent reuse in another lifecycle [88]; the steel and wood structural elements can be reused several times, down-cycled, and then recycled [86]. It must be said that these results can only be obtained due to an accurate study in the design phase and the level of detail of the techniques with which the connections are obtained [66]. 
The following Table 5 summarizes the degree of deconstruction of the different constructive systems, regarding the building layers.

Table 5. Deconstruction and reuse potential for the constructive system.

\begin{tabular}{ccccc}
\hline & & \multicolumn{2}{c}{ Deconstruction and Reuse Possibilities } \\
\cline { 3 - 5 } Layer & Building's part & Load-Bearing Walls & Rigid Frame & $\begin{array}{c}\text { Prefabricated } \\
\text { Components }\end{array}$ \\
\hline 1 & Technical installations & High & High & High \\
\hline 2 & Finishing & High & High & High \\
\hline 3 & Partitions & Variable & High & High \\
\hline 4 & Building envelope & Low & Variable & Variable \\
\hline 6 & Elevation structures & Low & Low & Medium \\
\hline
\end{tabular}

Finally, on the basis of the considerations made so far, it is possible to define a series of principles that can allow an easier and more efficient deconstruction of a building for the reuse and recycling of deconstructed components, regardless of the construction system and the materials used. These principles, which must necessarily be considered in the design phase to be effectively valid, can be summarized in major groups, depending on the strategy level:

1. Reduction of the building complexity. A good strategy to reduce complexity is to minimize the number of components, for example choosing fewer but larger elements. The use of modular and lightweight building components, manufactured in a factory and then assembled with codified procedures also contributes, improving buildability as well as simplifying the deconstruction process, as well as the storage and transportation in large units. In addition, it is possible to act on the connections between the elements: simplify the connections, making them visible or accessible, can allow efficient construction and deconstruction, reducing the need for a high range of tools as well as reducing the installation time. The simplification of the connections between non-structural elements allows separating the openings and the technical systems within non-structural elements for the further selective removal of the components.

2. Smart choice of materials and building components. The utilization of materials that are worth being reused and/or which are eco-compatible allow for adaptability and repurposing in the future in a new lifecycle. Materials such as wood, steel members, brick, and carpet tiles can easily be reused or refurbished, unlike materials such as cement, concrete, mortar, and plaster, which are often intended for landfill. Hazardous materials should be avoided, but if they are required for any reasons, it should be considered to tag them for a fast identification, so they can be properly handled at the end of their life. Using fewer materials also simplifies deconstruction, and when possible, the use of solid materials is preferable than the use of composites of dissimilar materials, as composites complicate the separation of individual materials for reuse.

3. Access to the deconstruction information. The realization of a database for the identification of materials and components can significantly contribute to successful deconstruction, for example realized through the BIM. For example, the record of digital drawings and photographs of building elements and technical systems before or during the construction of certain building components conveys information that is fundamental to carry out a functional deconstruction. In addition, a detailed deconstruction plan could be produced to ensure that the building is suitable for a successful deconstruction, including information about how to best reuse or recycle the deconstructed building's components. 
Table 6 summarizes the considerations written above about general deconstruction principles, to be applied generally, independently from the constructive system.

Table 6. Deconstruction principles.

\begin{tabular}{cc}
\hline \multicolumn{1}{c}{ Categories } & \multicolumn{1}{c}{ Principles } \\
\hline \multirow{2}{*}{ Reduction of building complexity } & Minimize the number of components \\
\cline { 2 - 2 } & Minimize the number of component types \\
\cline { 2 - 2 } Smart choice of materials & Use of modular components \\
\cline { 2 - 2 } & Use of lightweight components \\
\cline { 2 - 2 } & Use of prefabricated elements \\
\cline { 2 - 2 } & Realization of accessible technical installations \\
\cline { 2 - 2 } & Use of reusable materials \\
\cline { 2 - 2 } Access to the deconstruction information & Minimize the number of materials \\
\cline { 2 - 2 } & Minimize hazardous materials \\
\cline { 2 - 2 } & Matabase for the identification of components \\
\cline { 2 - 2 } & Technical drawings and pictures \\
\hline & Instructions about reuse and recycling \\
\hline
\end{tabular}

\section{Discussion}

The reuse of building components from constructions no longer in use is common throughout human history, assuming not only economic but also symbolic connotations. In more recent times, it has also taken on an ecological perspective, with the reuse and recycling of building materials aimed at the preservation of virgin materials and to keep the level of greenhouse gas emissions due to the construction and use of the building artefact low, as seen in the real-life examples discussed above. The reuse of building components is a direct consequence of the deconstruction activities: if it is well done, it allows obtaining quality materials and components that can be reused in new contexts with considerable environmental advantages, unlike demolition, which arbitrarily destroys a building, resulting in CDW that has to be landfilled.

Deconstruction principles and theories are closely linked to topics such as building constructive systems, type of materials, wet or dry connections, and method of realization, including made on-site or prefabricated: properties that affect the degree of deconstruction of a structure and the homogeneity of the dismounted components to be reused or recycled, instead of being landfilled. Deconstruction possibilities are undoubtedly influenced by the historical period in which the building was planned and built. Historic buildings, as well as most buildings built up to the early 2000s, were not specifically designed for deconstruction, as the lifecycle of the building has historically been rather linear, from construction to demolition, with landfill disposal of the construction and demolition waste. However, nowadays, in the context of the transition from a linear to a circular economy, this aspect is re-evaluated, with the prospect of having new lifecycles for the components that make up a building to be "deconstructed" and not demolished. There are many factors involved, and therefore, it is not easy to make an objective definition that can be applied as a rule to the entire architectural and construction panorama.

However, it may be worth thinking about the general criteria with which it is possible to achieve an efficient building deconstruction, regardless of the type of construction system. New building projects need to be studied already at the design phase under the viewpoint of deconstruction strategies [89]. This would ensure that the aspect of deconstruction is 
influencing the choice of constructive system and related materials, influencing the way to plan the complete lifecycle of a building from the beginning, including provisions for reuse and recycling of building components after their dismantling [17]. The application of strategies such as the reduction of the building complexity and the smart choice of materials in the design phase, as well as the production of the documentation needed for the overall knowledge of the building, can lead to successful deconstruction possibilities and related second-life options of the building components. In addition, the integration of the concepts of flexibility and adaptability in the design can allow future renovations or adaptations that may be required to extend the life of the building.

The costs of the deconstruction works can vary according to the size, location, and complexity of the project. Structural deconstruction is often more expensive than demolition, due to rising labor costs and the ratio of disposal, recycling, and recovery rates, but there are several environmental benefits. Deconstruction reduces the amount of CDW that is sent to landfills and redirects it back into the building lifecycle. Furthermore, the reuse of building materials reduces the demand for new building materials and thus reduces the amount of energy and resources used in their production, as well as the emissions related to their extraction. With planned landfill bans as well as upcoming subsidies and/or regulations/framework conditions that are in favor of the conservation of resources, the deconstruction of buildings will soon become normality in our society, and the costs will be part of any construction planning. In some countries, there is already an ordinance in place for the recycling of building materials and necessary deconstruction for all buildings above a certain size. The socio-economic benefits of deconstruction may include increased job opportunities, vocational training, historical preservation, availability of building materials, and small business development in economically depressed areas [90].

This research paper aims to start a broader discussion about building deconstruction, with the hope that subsequent studies and research may even arrive at an effective quantification of the resulting benefits. The next step will have to be an experimental and quantifiable approach, in order to refine the methodology and evaluate deconstruction with parameters that can allow a comparison with the traditional building planning processes.

\section{Conclusions}

As shown in Table 6, building deconstruction can be achieved by defining the following key points during the building planning and design process, independently from the constructive system type: (1) the reduction of building complexity, minimizing the number of components and types, favoring the modularity and lightness of the components, as well as the use of prefabrication and the simplification of the connections between the structural and non-structural elements; (2) smart choice of the materials to be used for the construction, favoring the use of reusable and eco-compatible materials and minimizing the use of hazardous materials and compositions; (3) allow the access to the information regarding building construction and deconstruction, with the instructions to follow for the correct identification and dismantling of components and the following instructions about their possible reuse or recycle; (4) define a deconstruction methodology for the whole planning process to include deconstruction principles at every lifecycle stage, so as to ascertain the potential for deconstruction and reuse at each stage of the process (design, production, construction, use, and end of life).

Building deconstruction can represent a viable and sustainable alternative to demolition, at least if there is an adequate study in the design phase. The building deconstruction of a building that was already predisposed to the disassembly and reuse of its components can represent an innovative way to redirect secondary resources into the building lifecycle. This can help to move from a linear model based on the consumption of resources toward a closed cycle of the use and reuse of materials, minimizing environmental impacts but at the same time providing the necessary resources for the construction of buildings.

Author Contributions: G.B. contributed mainly to the conceptualization, analysis, methodology, visualization, writing of the original draft, review, and editing; J.K. contributed mainly to funding ac- 
quisition, conceptualization, and review; J.Z. contributed mainly to conceptualization, methodology, and review; G.L. contributed mainly to funding acquisition, review, and supervision; T.F. contributed mainly to validation, review, and editing; D.Ö. contributed mainly to conceptualization, review, and editing. All authors have read and agreed to the published version of the manuscript.

Funding: This research was funded within the project "Urban Pop-Up Housing Environments and Their Potential as Local Innovation Systems" under the Vienna Science and Technology Fund (WWTF) with the project number ESR17-010.

Institutional Review Board Statement: Not applicable.

Informed Consent Statement: Not applicable.

Acknowledgments: Open access funding provided by BOKU Vienna Open Access Publishing Fund.

Conflicts of Interest: The authors declare no conflict of interest.

\section{References}

1. Crosthwaite, D. The global construction market: A cross-sectional analysis. Constr. Manag. Econ. 2000, 18, 619-627. [CrossRef]

2. Oberti, I. Prodotti Edilizi per Edifici Ecocompatibili. Uno Strumento per Orientare la Scelta; Maggioli: Rimini, Italy, 2014; ISBN 9788891602091.

3. Benachio, G.L.F.; do Carmo Duarte Freitas, M.; Tavares, S.F. Circular economy in the construction industry: A systematic literature review. J. Clean. Prod. 2020, 260, 121046. [CrossRef]

4. Cao, X.; Dai, X.; Liu, J. Building energy-consumption status worldwide and the state-of-the-art technologies for zero-energy buildings during the past decade. Energy Build. 2016, 128, 198-213. [CrossRef]

5. Baek, C.; Park, S.-H.; Suzuki, M.; Lee, S.-H. Life cycle carbon dioxide assessment tool for buildings in the schematic design phase. Energy Build. 2013, 61, 275-287. [CrossRef]

6. Solís-Guzmán, J.; Marrero, M.; Montes-Delgado, M.V.; Ramírez-de-Arellano, A. A Spanish model for quantification and management of construction waste. Waste Manag. 2009, 29, 2542-2548. [CrossRef]

7. Hart, J.; Adams, K.; Giesekam, J.; Tingley, D.D.; Pomponi, F. Barriers and drivers in a circular economy: The case of the built environment. Procedia CIRP 2019, 80, 619-624. [CrossRef]

8. Korhonen, J.; Honkasalo, A.; Seppälä, J. Circular Economy: The Concept and its Limitations. Ecol. Econ. 2018, 143, 37-46. [CrossRef]

9. Bocken, N.M.P.; de Pauw, I.; Bakker, C.; van der Grinten, B. Product design and business model strategies for a circular economy. J. Ind. Prod. Eng. 2016, 33, 308-320. [CrossRef]

10. Adams, K.T.; Osmani, M.; Thorpe, T.; Thornback, J. Circular economy in construction: Current awareness, challenges and enablers. Proc. Inst. Civ. Eng.-Waste Resour. Manag. 2017, 170, 15-24. [CrossRef]

11. Osobajo, O.A.; Oke, A.; Omotayo, T.; Obi, L.I. A systematic review of circular economy research in the construction industry. $S A S B E$ 2020. [CrossRef]

12. Kanters, J. Design for Deconstruction in the Design Process: State of the Art. Buildings 2018, 8, 150. [CrossRef]

13. Durmisevic, E.; Brouwer, J. Design aspects of decomposable building structures. In Design for Deconstruction and Materials Reuse; CIB Publication 272: Rotterdam, The Netherlands, 2002; pp. 81-103.

14. Jackson, M.; Livingston, D. Building A Deconstruction Company: A Training Guide for Facilitators and Entrepreneurs; Institute for Local Self-Reliance: Washington, DC, USA, 2001.

15. Bohne, R.A.; Wærner, E. Barriers for Deconstruction and Reuse/Recycling of Construction Materials in Norway; CIB Publication: Ottawa, ON, Canada, 2014; pp. 89-107.

16. Akinade, O.O.; Oyedele, L.O.; Bilal, M.; Ajayi, S.O.; Owolabi, H.A.; Alaka, H.A.; Bello, S.A. Waste minimisation through deconstruction: A BIM based Deconstructability Assessment Score (BIM-DAS). Resour. Conserv. Recycl. 2015, 105, 167-176. [CrossRef]

17. Akinade, O.O.; Oyedele, L.O.; Ajayi, S.O.; Bilal, M.; Alaka, H.A.; Owolabi, H.A.; Bello, S.A.; Jaiyeoba, B.E.; Kadiri, K.O. Design for Deconstruction (DfD): Critical success factors for diverting end-of-life waste from landfills. Waste Manag. 2017, 60, 3-13. [CrossRef] [PubMed]

18. Heinrich, M.; Lang, W. Materials Passports-Best Practice. Innovative Solutions for a Transition to a Circular Economy in the Built Environment; Technische Universität München: Munich, Germany, 2019; ISBN 978-3-941370-96-8.

19. Gepts, B.; Meex, E.; Nuyts, E.; Knapen, E.; Verbeeck, G. Existing databases as means to explore the potential of the building stock as material bank. IOP Conf. Ser. Earth Environ. Sci. 2019, 225. [CrossRef]

20. Chini, A.R.; Balachandran, S. Anticipating and Responding to Deconstruction through Building Design. In Design for Deconstruction and Materials Reuse; CIB Publication: Rotterdam, The Netherlands, 2002; Volume 272, pp. 175-185.

21. Bertino, G.; Fischer, T.; Puhr, G.; Langergraber, G.; Österreicher, D. Framework Conditions and Strategies for Pop-up Environments in Urban Planning. Sustainability 2019, 11, 7204. [CrossRef]

22. Pasca, M. Il Costruito Italiano: Tipologie, Problematiche, Interventi pre e Post Sisma; Sapienza University of Rome: Roma, Italy, 2012. 
23. Hein, M.F.; Houck, K.D. Construction Challenges of Adaptive Reuse of Historical Buildings in Europe. Int. J. Constr. Educ. Res. 2008, 4, 115-131. [CrossRef]

24. De Lachenal, L. Spolia-Uso e Reimpiego dell'Antico dal III al XIV Secolo; Longanesi: Milan, Italy, 1995; ISBN 8830413135.

25. Coarelli, F. Guida Archeologica di Roma, Illustrati. Arte e Costume; Mondadori: Milan, Italy, 1974.

26. Rutenburg, J.; Eckstein, A.M.; Heather, P.; Ward-Perkins, B. The Return of the Fall of Rome. Int. Hist. Rev. 2007, $29,109-122$. [CrossRef]

27. Adinolfi, R. Monumenti Cristiani Antichi nei Campi Flegrei; Editore Massimo: Naples, Italy, 1976.

28. Middleton, R.; Watkin, D. Neoclassical and 19th Century Architecture; Faber: London, UK, 1987; ISBN 0571150187.

29. Greenhalgh, M. The Survival of Roman Antiquities in the Middle Ages; Duckworth: London, UK, $1990 ;$ ISBN 0715621297.

30. Thomsen, A.; Schultmann, F.; Kohler, N. Deconstruction, demolition and destruction. Build. Res. Inf. 2011, 39, 327-332. [CrossRef]

31. Pompili, T. Networks Within Cities and Among Cities: A Paradigm for Urban Development and Governance; ERSA Conference Papers; ERSA: Wien, Austria, 2006.

32. European Commission. Resource Efficiency Opportunities in the Building Sector; EUR-Lex COM/2014/445; European Commission: Brussels, Belgium, 2014.

33. European Commission. Closing the Loop—An EU Action Plan for the Circular Economy; EUR-Lex COM/2015/614; European Commission: Brussels, Belgium, 2015.

34. European Commission. EU Circular Economy Action Plan: A new Circular Economy Action Plan for a Cleaner and More Competitive Europe. Available online: https:/ / ec.europa.eu/environment/circular-economy/ (accessed on 8 October 2020).

35. European Commission. A New Circular Economy Action Plan; EUR-Lex COM/2020/98; European Commission: Brussels, Belgium, 2020.

36. Partnership for Advancing Technology in Housing. A Report on the Feasibility of Deconstruction: An Investigation of DeconStruction Activity in Four Cities; US Department of Housing and Urban Development Office of Policy Development and Research: Washington, DC, USA, 2001.

37. Ellen MacArthur Foundation; Google. Accelerating the Circular Economy through Commercial Deconstruction and Reuse. Available online: https: / / www.ellenmacarthurfoundation.org/assets/downloads/google-deconstruction-and-reuse.pdf (accessed on 26 June 2020).

38. Ohms, P.; Andersen, C.E.; Rasmussen, F.N.; Ryberg, M.; Hauschild, M.; Birkved, M.; Birgisdottir, H. Assessing buildings' absolute environmental sustainability performance using LCA focusing on climate change impacts. IOP Conf. Ser. Earth Environ. Sci. 2019, 352, 12058. [CrossRef]

39. Tingley, D.D.; Davison, B. Design for deconstruction and material reuse. Proc. Inst. Civ. Eng.-Waste Resour. Manag. 2011, 164, 195-204. [CrossRef]

40. Elias-Özkan, S.T. An Overview of Demolition, Recovery, Reuse and Recycling practices in Turkey. In Design for Deconstruction and Materials Reuse; CIB Publication: Rotterdam, The Netherlands, 2002; Volume 272.

41. Crowther, P. Design for Disassembly-Themes and Principles. Environ. Des. Guide. 2005, 31, 1-7.

42. Sharma, N.K. Sustainable Building Material for Green Building Construction, Conservation and Refurbishing. Int. J. Adv. Sci. Technol. 2020, 29, 5343-5350.

43. Pulselli, R.M.; Simoncini, E.; Pulselli, F.M.; Bastianoni, S. Emergy analysis of building manufacturing, maintenance and use: Em-building indices to evaluate housing sustainability. Energy Build. 2007, 39, 620-628. [CrossRef]

44. Crowther, P. Design for Buildability and the Deconstruction Consequences. In Design for Deconstruction and Materials Reuse; CIB Publication: Rotterdam, The Netherlands, 2002; Volume 272.

45. Seemann, A.; Schultmann, F.; Rentz, O. Cost-effective deconstruction by a combination of dismantling, sorting and recycling processes. In Design for Deconstruction and Materials Reuse; CIB Publication: Rotterdam, The Netherlands, 2002 ; Volume 272.

46. Reinhold, M.; Mueller, A. Lightweight aggregate produced from fine fractions of construction and demolition waste. In Design for Deconstruction and Materials Reuse; CIB Publication: Rotterdam, The Netherlands, 2002; Volume 272.

47. Mueller, A.; Stark, U. Recycling of clay brick. In Design for Deconstruction and Materials Reuse; CIB Publication: Rotterdam, The Netherlands, 2002.

48. Schultmann, F.; Renz, O. Resource-constraint project scheduling for deconstruction projects. In Design for Deconstruction and Materials Reuse; CIB Publication: Rotterdam, The Netherlands, 2003.

49. Giglio, F. Controlling environmental impacts in the dismantling phase. In Design for Deconstruction and Materials Reuse; CIB Publication: Rotterdam, The Netherlands, 2002; Volume 272.

50. Bart, J.t.D.; Kowalczyk, T. Design for recycling. In Design for Deconstruction and Materials Reuse; CIB Publication: Rotterdam, The Netherlands, 2002; Volume 272.

51. Macozoma, D.S. Understanding the Concept of Flexibility in Design for Deconstruction. In Design for Deconstruction and Materials Reuse; CIB Publication: Rotterdam, The Netherlands, 2002.

52. Pearlmutter, D.; Theochari, D.; Nehls, T.; Pinho, P.; Piro, P.; Korolova, A.; Papaefthimiou, S.; Mateo, M.C.G.; Calheiros, C.; Zluwa, I.; et al. Enhancing the circular economy with nature-based solutions in the built urban environment: Green building materials, systems and sites. Blue-Green Syst. 2020, 2, 46-72. [CrossRef]

53. Arslan, H.; Cosgun, N. Reuse and recycle potentials of the temporary houses after occupancy: Example of Duzce, Turkey. Build. Environ. 2008, 43, 702-709. [CrossRef] 
54. Carpinteri, A. Structural Mechanics: A Unified Approach; CRC Press: Boca Raton, FL, USA, 1997.

55. Waddell, J. Bridge Engineering; John Wiley \& Sons: Hoboken, NJ, USA, 1916.

56. Fascia, F.; Iovino, R. La Struttura in Cemento Armato per l'Architettura. Tecnica e Tecnologia; Aracne: Roma, Italy, 2008; ISBN 9788854819139.

57. De Sivo, B.; Iovino, R.; Cito, G. Appunti di Architettura Tecnica, 5th ed.; Cuen: Naples, Italy, 1995; ISBN 8871462653.

58. Aveta, A. Materiali e Tecniche Tradizionali nel Napoletano: Note per il Restauro Architettonico; Arte Tipografica: Naples, Italy, 1990.

59. Korol', E.A.; Kustikova, Y.O. Constructive systems, load-bearing and enclosing structures of high-rise buildings. E3S Web Conf. 2018, 33, 1043. [CrossRef]

60. Amati, C. Dell'architettura di Marco Vitruvio Pollione; Giacomo Pirola: Milan, Italy, 1829.

61. Pollio, V. Vitruvius: Ten Books on Architecture; Cambridge University Press: New York, NY, USA, 1999; ISBN 9780521553643/ 9780521002929.

62. Rafi, M.M.; Nasir, M.M. Models for Prediction of 28-Day Concrete Compressive Strength. J. Test. Eval. 2016, 44, 1217-1228. [CrossRef]

63. Xue, J.; Qi, L. Experimental studies on steel frame structures of traditional-style buildings. Steel Compos. Struct. 2016, 22, 235-255. [CrossRef]

64. Magar, J.; Kudtarkar, A.; Pachpohe, J.; Nagargoje, P. Study and Analysis of Types of Foundation and Design Construction. IRJET 2020, 7, 3301-3307.

65. Elam, J.; Björdal, C. A review and case studies of factors affecting the stability of wooden foundation piles in urban envi-ronments exposed to construction work. Int. Biodeterior. Biodegrad. 2020, 148, 104913. [CrossRef]

66. Smith, R.E. Prefab Achitecture. A Guide for Architects and Construction Professionals; John Wiley \& Sons: Hoboken, NJ, USA, 2011; ISBN 9780470880463.

67. Gibb, A.; Isack, F. Re-engineering through pre-assembly: Client expectations and drivers. Build. Res. Inf. 2003, 31, 146-160. [CrossRef]

68. Estévez, B.; Aguado, A.; Josa, A. Environmental impact of concrete recycling, coming from CDW. In Design for Deconstruction and Materials Reuse; CIB Publication: Rotterdam, The Netherlands, 2003; Volume 287.

69. Chadha, B. Off-site manufacturing-A way towards lean construction. J. Civ. Eng. Environ. Technol. 2015, 2. ISSN 2349879X.

70. Dietsch, P.; Tannert, T. Assessing the integrity of glued-laminated timber elements. Constr. Build. Mater. 2015, 101, 1259-1270. [CrossRef]

71. Tam, V.W.; Tam, C.M.; Zeng, S.X.; Ng, W.C. Towards adoption of prefabrication in construction. Build. Environ. 2007, 42, 3642-3654. [CrossRef]

72. Bonfanti, C.; Carabellese, A.; Toniolo, G. Strutture Prefabbricate-Catalogo delle Tipologie Esistenti; Assobeton: Milano, Italy, 2008.

73. Johnson, C. Impacts of prefabricated temporary housing after disasters: 1999 earthquakes in Turkey. Habitat Int. $2007,31,36-52$. [CrossRef]

74. Shumaker, D. Materials and Design for Deconstruction. Available online: https://soa.utexas.edu/sites/default/disk/analytic\$ backslash\$_tools/analytic\$ \backslash\$_tools /09\$ backslash\$_02\$ backslash\$_su\$ \backslash\$_shumaker\$ $\backslash$ backslash\$_ daniel\$ \backslash\$_paper\$backslash\$_ml.pdf(25/3/2019) (accessed on 30 June 2020).

75. Zaman, A.; Arnott, J.; Mclntyre, K.; Hannon, J. Resource Harvesting through a Systematic Deconstruction of the Residential House: A Case Study of the 'Whole House Reuse' Project in Christchurch, New Zealand. Sustainability 2018, 10, 3430. [CrossRef]

76. Passivhaus Institut. Passivhaus Institut. Available online: https:/ / passiv.de/ (accessed on 14 July 2020).

77. Passive House Institute. Passive House Institute. Available online: https:/ / passivehouse.com/ (accessed on 29 June 2020).

78. Foster, J.; Sharpe, T.; Poston, A.; Morgan, C.; Musau, F. Scottish Passive House: Insights into Environmental Conditions in Monitored Passive Houses. Sustainability 2016, 8, 412. [CrossRef]

79. Circl. The Making of Circl. Available online: https:/ / circl.nl/themakingof/en/ (accessed on 11 November 2020).

80. Mondal, G.; Jain, S.K. Design of non-structural elements for buildings: A review of codal provisions. Indian Concr. J. 2005, 79, 22-28.

81. Johnson, C. Strategies for the Reuse of Temporary Housing. In Urban Transformation-Holcim Forum; Ruby Press: Berlin, Germany, 2007; pp. 325-331.

82. Zhang, C.; Hu, M.; Yang, X.; Miranda-Xicotencatl, B.; Sprecher, B.; Di Maio, F.; Zhong, X.; Tukker, A. Upgrading construction and demolition waste management from downcycling to recycling in the Netherlands. J. Clean. Prod. 2020, 266, 121718. [CrossRef]

83. Mohammed, B. Behavior of the Dry Bed Joint in the Mortarless Interlocking Masonry System: An Overview. Civ. Eng. Res. J. 2018, 4. [CrossRef]

84. Collins, J.A.; Busby, H.R.; Staab, G.H. Mechanical Design of Machine Elements and Machines: A Failure Prevention Perspective, 2nd ed.; Wiley: Hoboken, NJ, USA, 2010; ISBN 0470413034.

85. Salama, W. Design of concrete buildings for disassembly: An explorative review. Int. J. Sustain. Built Environ. 2017, 6, 617-635. [CrossRef]

86. Durmisevic, E.; Noort, N. Re-use potential of steel in building construction. In Design for Deconstruction and Materials Reuse; CIB Publication: Rotterdam, The Netherlands, 2003; Volume 287.

87. Madanayake, U. Sustainable implications of building reuse and adaption. In Proceedings of the Third World Construction Symposium 2014: Sustainability and Development in Built Environment, Colombo, Sri Lanka, 20-22 June 2016; pp. 139-158. 
88. Androsevic, R.; Durmisevic, E.; Brocato, M. Measuring reuse potential and waste creation of wooden façades. IOP Conf. Seri. Earth Environ. Sci. 2019, 225, 12017. [CrossRef]

89. Addis, W.; Schouton, J. Principles of Design for Deconstruction to Facilitate Reuse and Recycling; CIRIA: London, UK, 2004; ISBN 9780860176077.

90. Lassandro, P. Deconstruction case study in southern Italy: Economic and environmental assessment. In Design for Deconstruction and Materials Reuse; CIB Publication: Rotterdam, The Netherlands, 2003; Volume 287. 